NBER WORKING PAPER SERIES

\title{
ENTREPRENEURSHIP DURING THE COVID-19 PANDEMIC: EVIDENCE FROM THE BUSINESS FORMATION STATISTICS
}

\author{
John C. Haltiwanger \\ Working Paper 28912 \\ http://www.nber.org/papers/w28912 \\ NATIONAL BUREAU OF ECONOMIC RESEARCH \\ 1050 Massachusetts Avenue \\ Cambridge, MA 02138 \\ June 2021
}

This paper, without implication, draws on collaborative research with numerous colleagues I have worked with in the development and analysis of the Business Formation Statistics (BFS). The research and development papers for the BFS with these colleagues are cited extensively in the text and included in the references. This paper uses only public domain data from the BFS and other sources. Thanks to Lucia Foster, Josh Lerner, Scott Stern, and participants at the 2021 NBER Conference on Entrepreneurship and Innovation Policy and the Economy for helpful comments on an earlier draft and to Chris Roudiez for excellent research assistance. The views expressed in the paper are those of the author alone. The views expressed herein are those of the author and do not necessarily reflect the views of the National Bureau of Economic Research.

NBER working papers are circulated for discussion and comment purposes. They have not been peer-reviewed or been subject to the review by the NBER Board of Directors that accompanies official NBER publications.

(C) 2021 by John C. Haltiwanger. All rights reserved. Short sections of text, not to exceed two paragraphs, may be quoted without explicit permission provided that full credit, including () notice, is given to the source. 
Entrepreneurship During the COVID-19 Pandemic: Evidence from the Business Formation Statistics

John C. Haltiwanger

NBER Working Paper No. 28912

June 2021

JEL No. E32,L25,L26

\begin{abstract}
Applications for new businesses from the U.S. Census Bureau's monthly and weekly Business Formation Statistics (BFS) fell substantially in the early stages of the pandemic but then surged in the second half of 2020. This surge has continued through May 2021. The pace of applications since mid-2020 is the highest on record (earliest data available is 2004). The large increase in applications is for both likely new employers and nonemployers. These patterns contrast sharply with those in the Great Recession when applications for likely new employer businesses and in turn actual startups of employer businesses declined sharply and persistently. The surge in new business applications has been uneven across sectors. Ten 3-digit NAICS industries account for $75 \%$ of the surge. Dominant industries include Nonstore Retail (alone accounting for 33\% of the surge), Professional, Scientific and Technical Services, Truck Transportation, and Accommodation and Food Services. Given that existing small businesses in Retail Trade and Accommodation and Food Services have suffered especially large declines in the pandemic, these patterns are consistent with restructuring induced by the pandemic.
\end{abstract}

John C. Haltiwanger

Department of Economics

University of Maryland

College Park, MD 20742

and NBER

haltiwan@econ.umd.edu 
The COVID-19 induced recession (henceforth COVID-19 Recession) began with an extraordinarily large contraction in economic activity. The net employment contraction between February and April 2020 exceeded 20 million for total nonfarm employment. Since then, employment has recovered substantially but as of April 2021 is still more than 8 million below the level in February 2020. ${ }^{2}$ The massive contraction and recovery have been very uneven. Existing small businesses have been hit especially hard especially in sectors such as Accommodations and Food Services, Health Services, and Other Services where remote work and remote interactions between businesses and consumers are difficult. Even in sectors that have experienced a net increase in jobs from February 2020 to early 2021 such as Finance and Insurance, existing small businesses have exhibited indicators of negative net growth, business sentiment and recovery through early $2021 .^{3}$

This characterization of existing small businesses being hit very hard with only limited recovery contrasts with the patterns of new business applications from the Business Formation Statistics (BFS). After an initial sharp decline from late March through May, new business applications started to surge by June 2020. This surge has continued through May 2021. Overall, calendar year 2020 is the highest year on record for new business applications since 2004 (the first year the BFS is available). ${ }^{4}$ The surge in new business applications in 2020 and

\footnotetext{
${ }^{2}$ Statistics from www.bls.gov for Current Establishment Survey total non-farm employment.

${ }^{3}$ See Buffington et al. (2021) for details about this characterization of the impact on existing small businesses. The evidence briefly summarized here is from the Census Small Business Pulse Survey (SBPS) discussed at length in this paper. Fairlie (2020) presents evidence that existing small businesses were hit hard by examining selfemployment patterns from the CPS. Abraham et al. (2021) raise questions about how well the CPS captures selfemployment relative to the administrative data. The concerns they raise apply primarily the unincorporated selfemployment statistics from the CPS. Haltiwanger and Rendell (2021) find that the while the new applications for likely employers closely tracts actual new employer startups from the BDS (consistent with the evidence shown here) that the flow into unincorporated self-employment businesses does not match the patterns from the BFS or the BDS in terms of new employer startups.

${ }^{4}$ The surge in new business applications in the BFS are matched by other sources such as the Startup Cartography Project (SCP) as reported in Fazio et al. (2021). The latter covers only 8 states but offers rich and novel findings into how these patterns vary across narrow geographic areas. See further discussion below in section III.
} 
2021 includes a surge in applications for both likely employer and likely nonemployer businesses. These patterns contrast not only with the experiences of existing small businesses in 2020 but also with business applications in the Great Recession. In the Great Recession, new applications for likely employers as well as actual employer business startups declined sharply.

The surge in new applications in 2020 and 2021 for likely employer businesses is surprising especially given historical experience and the evidence and expectations early in the pandemic. The decline in new applications for likely employer businesses early in the pandemic exhibited a similar pattern to the sharp downturn after the collapse of Lehman Brothers in the Fall 2008. ${ }^{5}$ Even some aspects of the rapid fiscal policy response did not appear to bode well for starting new employer businesses in the pandemic. A key component of the CARES act of March 2020 is the Payroll Protection Program (PPP) designed to protect jobs of existing small businesses. Given the unprecedented nature of the shutdown of the economy in the pandemic, it is not surprising that there was strong support to protect jobs in this manner. However, from the perspective of economic theory (see, e.g., Acemoglu et al. (2018)) subsidizing incumbents can potentially suppress business entry. Viewed from this perspective, the surge in new business applications in 2020 that has continued into 2021 is even more surprising. The analysis in this paper provides insights and guidance into the underlying likely sources of these surprising patterns.

In considering these issues, it is critical to distinguish between new applications for likely employer and likely nonemployer businesses. In the Great Recession, applications for likely

\footnotetext{
${ }^{5}$ New applications for likely employers and actual employers started to decline prior to the Great Recession at least partly due to the decline in financial conditions (e.g., the collapse in housing prices) that preceded the Great Recession. See Fort et al. (2014) and Davis and Haltiwanger (2019) for more analysis of the decline in employer startups in the Great Recession. See Dinlersoz et al. (2021) for an in-depth comparison of business applications in the Great Recession relative to the COVID-19 Recession.
} 
new nonemployer businesses increased consistent with a countercyclical component of selfemployment. In the pandemic, the surge in new business applications has been especially large for likely nonemployer businesses with the surge four times larger than the increase in the Great Recession.

The BFS is derived from administrative data from the Internal Revenue Service (IRS) on Employer Identification Number (EIN) applications. All employer businesses in the United States are required to have an EIN to file payroll taxes. New non-employer businesses also file for an EIN if forming a partnership or an incorporated business. Even new sole proprietor nonemployers often file for an EIN to facilitate their business activity (e.g., working with other businesses or opening a business bank account). The EIN application form includes the name and address of the applicant and business, business start date, type of business entity, principal industry, and planned date of initial wage payments (if applicable). The filing date and business location information are used to aggregate individual applications to weekly and monthly frequency. The IRS transmits these applications to Census on a weekly flow basis in virtually real time. ${ }^{6}$

The detailed information on the application permits decomposing new business applications (BA) into likely employers and likely nonemployers. Businesses that have a high propensity of becoming an employer business based upon, for example, the application indicating planned wages are designated as High-Propensity Business Applications (HBA). Consistent with Bayard et al. (2018), evidence presented in this paper shows that there is a tight

\footnotetext{
${ }^{6}$ Bayard et al. (2018) describe in detail how certain types of applications are automatically excluded from the BFS since they are tax entities not for engaging as employer or nonemployer self-employment activity. For example, applications for trusts and estates are excluded. It is also worth noting that the application process itself is largely online and automated so that disruptions in IRS activity early in the pandemic have apparently had little or no impact on the tracking and reporting of applications.
} 
relationship between HBA and actual new employer startups over the subsequent 8 quarters. The difference between BA and HBA is referred to as likely nonemployers (NHBA) in this paper and the analysis below shows that fluctuations in NHBA closely track fluctuations in nonemployers. The public domain BFS also includes series by geography (state) and industry. The geographic and industry variation permits analysis of the dispersion in entrepreneurial activity across sectors and locations.

This surge in new business applications in the pandemic is of interest given the important role that employer startups play in job creation, innovation, and productivity growth (Haltiwanger et al. 2013; Alon et al. 2018; Acemoglu et al. 2018; and Guzman and Stern, 2020). More generally, new employer startups are an important point of the ongoing creative destruction dynamics in the U.S. economy (see, e.g., Davis and Haltiwanger, 1999). The surge in likely nonemployer new applications is also of interest given increasingly important role that gig workers are playing in the U.S. economy (see, e.g., Abraham et al. 2021).

The potentially changing nature of the relationship between applications and transitions in the pandemic period necessitates appropriate caution in interpreting the patterns of nascent entrepreneurship from the BFS during the pandemic period. Still, the historically tight relationships indicate that these have been highly predictive indicators of entrepreneurship in the past. In addition, the patterns of new applications by sector and industry during the pandemic presented below are consistent with the shifts towards remote activity interactions between businesses and workers (i.e., telework) and businesses and consumers (i.e., online retail and restaurant purchases with accompanying delivery to customers residential locations). These patterns suggest that the surge in new applications reflect ongoing restructuring in the economy 
induced by the pandemic. There are open questions about how much of this will persist and, to the extent there is persistence, whether the pandemic is accelerating pre-pandemic trends.

The paper proceeds as follows. Section II provides a description of the BFS to help interpret the striking patterns of this novel data. Section III presents the main results providing insights on the basic patterns, the contrast between the patterns in the COVID-19 recession and the Great Recession, and the sectoral and geographic differences in applications during the pandemic. Analysis of the relationship between new business applications and indicators of business and worker turnover is presented in section IV. Section V includes a discussion of whether programs like the Paycheck Protection Program (PPP) have impacted the observed surge in new business applications. Concluding remarks, including discussion of next steps for research, are provided in Section VI.

\section{Description of Business Formation Statistics}

The public domain BFS series are available weekly from 2006:w1 through the present and monthly from 2004:m7 through the present. ${ }^{7}$ The weekly series include total applications (BA), high propensity applications (HBA), applications with planned wages (WBA), and applications for corporations (CBA) at the national and state level (all not seasonally adjusted). The monthly series include all the same application series and some formation series. For the latter, actual new employer business formations from these applications over the next four and eight quarters (BF4Q and BF8Q) as well as projections for new business formations (PBF4Q and PBF8Q) are released at the national, sectoral, and state level. The series are available both seasonally adjusted and unadjusted (only the seasonally adjusted monthly series are used in the current paper). The BFS data are very timely: weekly data are released for a given reference

\footnotetext{
${ }^{7}$ As of the writing of this paper, the weekly series is available though 2021:w21 (through May 29, 2021) and the monthly series is available though 2021:m4.
} 
week on the Thursday after the reference week and monthly data are released within two weeks of the end of the reference month. The NHBA series used in this paper is constructed directly from the difference between BA and HBA.

Applications designated likely employers (HBA) include applications that have at least one of the following indicators on the application: (i) are from corporations, (ii) indicate hiring an employee (iii) indicate a first wages paid/planned date, and (iv) in certain industries: manufacturing, food and accommodation services, health care, and part of retail. Overall, HBA have less than 50\% likelihood of becoming employer businesses within 8-quarters after application, but fluctuations in HBA (see Figure 2 below) closely track actual employer startups. Applications denotes as likely nonemployers (NHBA) have a low probability of becoming employer businesses of only 3.8\%. ${ }^{8}$ However, as shown below fluctuations in NHBA closely track fluctuations in nonemployers.

The empirical model used to predict transitions for the series PBF4Q and PBF8Q is described in detail in Bayard et al. (2018). Briefly, the projections are based on a linear probability model (LPM), which relates observed transitions of business applications to employer businesses in the Longitudinal Business Database (LBD) to a set of predictors from the EIN application form. The variables include indicators of the business start date, type of entity, industry, limited liability status, reason for applying, and wage date. The model also controls for location (state), week of application submission within the year, presence of prior EIN, and whether the application indicates a trade name, or a distinct business address. The covariates of the empirical model also include interactions between industry, wage date, type of entity, and reason for applying. Figure 6 of Bayard et al. (2018) shows that projected transitions track actual

\footnotetext{
${ }^{8}$ See Bayard et al. for the rates of employer business formation associated with different application characteristics (2018).
} 
transitions closely, both within and out of sample. In the analysis in this paper, the focus is on the spliced business formations using the actual formations up through 2018 and the projected transitions thereafter. During the period that the actual and projected transitions are available (from 2004 to 2018) these series closely track each other.

\section{Evidence on Entrepreneurship in the Pandemic}

This section starts with some basic facts about business application series before proceeding to analyses from cyclical, sectoral, and spatial perspectives.

\section{A. Basic Facts}

The patterns of new business applications (BA, HBA, and NHBA) from 2004:m7 through 2021:m4 are shown in Panel A of Figure 1. Panel B repeats Panel A but narrows the time frame to 2019:m1 to 2021:m4 to permit greater focus on the pandemic. The upward trend in NHBA and the downward trend in HBA from 2004:m7 through 2020:m2 are evident. ${ }^{9}$ At the outset of the pandemic there is a sharp decline in BA, HBA and NHBA in March through May 2020. However, by June 2020 the number of applications of all types exceeds any month from January 2019 through February 2020. The surge in applications of all types peaks in July 2020 but the numbers in August 2020 to March 2021 exceed the number of applications in all prior months back to 2004:m7 for BA and NHBA and in all prior months back to 2007:12 for HBA.

HBA tracks actual (through 2018) and projected transitions to new employer startups as shown in Figure 2. Indices are depicted in Figure 2 given differences in levels and the projected transition series is for transitions to employer business over the next 8 quarters. The transition rate is lower than 50\% (see Bayard et al. 2018) even for HBA, highlighting that HBA should be interpreted as an indicator of nascent entrepreneurship in terms of potential new employer

\footnotetext{
${ }^{9}$ In fact, HBA is greater than NHBA from 2004 through 2008 when NHBA begins to be larger than HBA.
} 
startups. However, since the correlation in the monthly indices series is 0.88 it is apparent that variation in this indicator of nascent entrepreneur closely tracks variation in new employer startups. ${ }^{10}$ It is, of course, of great interest to identify the determinants of the applications that successfully make the transition to an actual employer startup. Bayard et al. (2018) highlight that there is enormous spatial variation in both application and the transition rates. Active research is underway to identify the sources of such variation.

The BFS does not provide indicators of actual or projected new nonemployers. However, a comparison of NHBA with published nonemployer statistics indicates a tight relationship. Figure 3 presents indices of the actual total number of nonemployers and the predicted number of nonemployers. ${ }^{11}$ The correlation between the actual and projected series is almost one.

\section{B. Cyclical}

The weekly data enable a detailed comparison of the dynamics of new business applications in the COVID-19 Recession and the Great Recession. For both recessions, a simple event study characterization of the dynamics is instructive where the patterns of business applications prior to and after a reference week 0 are examined (see Dinlersoz et al. (2021) for a related empirical analysis). ${ }^{12}$ For the COVID-19 Recession, week (0) is defined as week 10 of 2020 (the week ending March 13, 2020). Given the weekly data are not seasonally adjusted, it is

\footnotetext{
10 This is the correlation through 2018 using only actual startups.

11 The predicted number of nonemployers uses the actual number of nonemployers in 2006, exit rates from nonemployers (from Davis et al. 2009), and projecting entry into nonemployers from NHBA (see appendix for details). Appropriate caution for interpreting this calculation as this is a crude calculation. NHBA only includes applications for new EINs that are likely nonemployers. Nonemployers includes sole proprietors without EINs. The index approach helps overcome these limitations.

12 Dinlersoz et al. (2021) conduct a closely related but more sophisticated econometrics exercise using state-level weekly data. The findings reported here are consistent with their findings. This closely related work using a regression framework enables establishing that the variation presented here reflects not only economically significant but also statistically significant differences. The findings reported here include applications through April 2021 while Dinlersoz et al. (2021) report pattens through the end of 2020. Also, Dinlersoz et al. (2021) use DHS growth rates to accommodate the state-level variation they exploit while the analysis reported here uses national totals.
} 
instructive to compute the cumulative difference (backwards and forwards) relative to week 10 of 2020 with the cumulative difference relative to week 10 of a base period which we choose to be week 10 of 2018. For the Great Recession, the reference week 0 for the crisis that is considered is week 37 of 2008 (the week just prior to the Lehman Brothers collapse). The cumulative differences computed for the Great Recession use 2006 as the base period (with week 0 of the base period being week 37 of 2006). The cumulative differences are reported 63 weeks after the reference week 0 for both the Great Recession and the COVID-19 recession. For the latter, this reflects cumulative differences through May 29, 2021.

The patterns for the COVID-19 Recession are depicted in the upper panel of Figure 4. Prior to the crisis (i.e., prior to week 10 in 2020) applications for likely employers in the first 10 weeks of 2020 were similar to those for the base period of 2018. As such there is not much cumulative difference going backwards. After week 0 of the crisis, applications fell initially in 2020 relative to base period of 2018 but then have risen substantially. Through May 2021, new applications for likely employers were almost 500K greater over a similar period from March 2018 through May 2019. For likely nonemployers, the first part of 2020 had slightly higher applications than the comparable first part of 2018. Applications for nonemployers also declined initially early in the crisis but then quickly rebounded. Through May 2021, new applications for likely nonemployers were more than 1.3 million greater than a similar period from March 2018 through May 2019.

The lower panel depicts the same exercise for the Great Recession. The patterns are dramatically different. For likely employer applications, applications in the 10 weeks prior to the reference week in 2006 are higher than those in 2008. This is evident from Figure 1. After the Lehman Brothers collapse, applications for likely employers fell substantially for the 63 
subsequent weeks compared to the reference period. These patterns for likely employers in the Great Recession are also evident for actual new employer startups as shown in Figure 2.

The decline in actual employer startups in the Great Recession has been examined at length elsewhere (see Davis and Haltiwanger (2019) and references therein). The analysis here highlights the decline in actual entrepreneurship is anticipated by the observed decline in nascent entrepreneurship in the BFS. One interesting feature of the decline in both nascent and actual entrepreneurship for employer businesses over this period is that the decline began before the start of the Great Recession (December 2007) and as such prior to the Lehman Brothers collapse in September 2008. While the trend decline in the pace of actual entrepreneurship precedes 2006, the sharp cyclical downturn in employer startups that is often linked to the Great Recession begins in 2006 prior the start of the Great Recession. Davis and Haltiwanger (2019) highlight that the sharp decline in actual entrepreneurship that began in 2006 is associated with the sharp decline in housing prices that also began in 2006. An interesting area for future research is to investigate the differing impact of changing financial conditions on nascent versus actual entrepreneurship.

Turning back to Figure 4, for nonemployers the 10 weeks in 2008 prior to Lehman collapse had similar patterns than the comparable period in 2006. After Lehman's collapse, applications for nonemployers increased relative to the comparable period in 2006. While this is qualitatively similar to the COVID-19 Recession, the latter is four times larger than the increase in the Great Recession. Moreover, by 52 weeks after the crisis week 0 in the Great Recession, the cumulative difference had stopped increasing. In contrast, for the COVID-19 Recession, the cumulative difference continued to surge for weeks 52 to 63. 
Why are the patterns for applications for likely employers and likely nonemployers so different between the Great Recession and the COVID-19 Recession? This is an open and active area of current research; however, some factors already appear to be important. First, financial conditions are dramatically different across these episodes. The financial crisis that is at the root of the Great Recession included a decline in housing prices, a decline in net worth for households, and substantial challenges for bank balance sheets. Small business lending collapsed over this period. Some of this reflected likely reflected demand side factors but Davis and Haltiwanger (2019) identify a credit supply channel that adversely impacted young businesses. In contrast, financial markets have been robust in the COVID-19 Recession with housing prices rising and financial intermediaries much healthier in this period.

Secondly, the COVID-19 Recession has induced a change in the structure of the U.S. economy towards more remote activity and this provides incentives for new businesses to explore such potential opportunities. The restructuring component of the surge in business applications can be investigated by examining the changing sectoral composition of new business applications. This is the topic of the next section.

\section{Sectoral}

The surge in new business applications in the pandemic has been uneven across industries. The top panel of Figure 5 shows the monthly patterns of applications for likely new employers for selected sectors for the 2004:m7 to 2021:m4 period while the bottom panel shows the patterns for the 2019:m1-2021:m4 period. The surge in new applications for likely employers in the pandemic is dominated by Retail Trade but other sectors with substantial 
increases including Food and Accommodations and Health Services. ${ }^{13}$ New applications for likely nonemployers for selected sectors are reported in Figure 6. The surge in 2020 is dominated by Retail Trade accompanied by Professional, Scientific and Technical Services; Construction; and Trucking and Warehousing.

A special release in October 2020 of the weekly BFS covering 2019:w1-2020:w40 provides more industrial detail for overall applications. Figure 7 presents the 3-digit NAICS sectors with the largest change in the number of new applications over the first 40 weeks of 2020 compared to the first 40 weeks of 2019. The largest change in share is for Nonstore Retailers which increased its number of applications by about 200K over this period. In 2019, Nonstore Retailers accounted for only $9 \%$ of overall applications. Thirty-three percent of the increase in applications from 2019 to 2020 is accounted for by this industry alone. The top ten industries listed in Figure 7 account for $75 \%$ of the increase in applications over the first 40 weeks of 2020 compared to 2019.

Figures 5-7 highlight the uneven nature of surge in applications across industries. Figure 8 presents the between sector dispersion in year-over-year growth rates of the monthly growth rates of HBA and NHBA. The top panel shows that dispersion in new application growth rates across sectors for HBA rose in the Great Recession, declined in its aftermath, and exhibited an upward trend through 2019. The dispersion fell in the early stages of the pandemic but has risen steadily since May 2020.

Between sector dispersion in NHBA did not change much in the Great Recession but like dispersion for HBA has exhibited a positive trend from 2012 to 2019. After falling early in the

\footnotetext{
${ }^{13}$ Appropriate caution is required in interpreting the results for Accommodations and Food Services as well as Health Services given that applications in both sectors are automatically classified into HBA. As explained in Bayard et al. (2018) applications in those sectors have a higher-than-average propensity of becoming employers.
} 
pandemic, between sector dispersion in NHBA growth rates has risen sharply since March 2020. Dispersion peaked in August 2020 and has fallen since then but remains above levels pre-2020.

All this highlights that the pandemic surge in business applications is associated with intensified restructuring on several dimensions. For one, entry by itself an important component of restructuring in terms of business turnover. Second, the uneven patterns across sectors that change rapidly over a short period of time suggests that the restructuring has an important between sector component. The sectors with especially high business application rates provide guidance about the nature of this restructuring. The dramatic rise in sectors such as Nonstore Retail is consistent with the shift towards remote interactions between businesses and consumers. The rise in applications in sectors such as Retail Trade and Food and Accommodations are notable given the employment losses in those sectors as well as the especially adverse effects of the pandemic on existing small businesses in these sectors. From Feb 2020 to April 2021 employment losses in these two sectors are $400 \mathrm{~K}$ and 2.2 million, respectively. ${ }^{14}$

Putting these BFS patterns into perspective, the SBPS from the Census Bureau highlights that existing small businesses have been pivoting their business operations during the pandemic in several ways (see Buffington et al. (2021)). Remote work activity has increased dramatically especially in some sectors like Information. Moreover, online activity connecting existing small businesses to customers has increased substantially. The surge in new applications mirrors this shift in business activity. However, strikingly the SBPS shows that even by January 2021, existing small businesses in all sectors exhibit negative indicators in terms of growth, business sentiment and expectations. The surge in applications in the BFS concentrated in specific sectors

\footnotetext{
${ }^{14}$ Statistics from www.bls.gov CES employment by sector.
} 
suggests the restructuring involves a shift away from existing small businesses towards new businesses.

\section{Spatial}

The surge in new business applications in the pandemic has also been uneven across locations. The top panel of Figure 9 shows the monthly patterns of applications for likely new employers for selected states for the 2004:m7 to 2021:m4 period while the bottom panel shows the patterns for the 2019:m1-2021:m4 period. For this state-level analysis, index numbers equal to one on average in 2006 to adjust for the size of the state at specific point in time (2006). The surge in new applications for likely employers in the pandemic is especially large in Georgia, Florida and Texas compared to California, New York, and New Jersey. New applications for likely nonemployers for the same selected states are reported in Figure 10. The surge in 2020 for likely nonemployers is again especially large in Georgia, Florida and Texas compared to California, New York, and New Jersey.

Figures 9 and 10 highlight the uneven nature of surge in applications across states. ${ }^{15}$

Figure 11 presents the between state dispersion in year-over-year growth rates of the monthly growth rates of HBA and NHBA. The top panel shows that dispersion in new application growth rates across states changed little in the Great Recession and has been reasonably stable through 2019. The dispersion rose substantially in May through July and has declined since then. However, it remains at a level higher than pre pandemic.

\footnotetext{
${ }^{15}$ Fazio et al. (2021) present evidence across 8 states that is broadly consistent with that presented here in terms of an uneven surge in applications across geographic areas. A novel and interesting finding in this work from the SCP project is that the surge in new firm formation has been especially in zip codes including a high proportion of African-American residents and in particular higher median income African-American neighborhoods. Investigating the cross sectional and time series patterns of entrepreneurship by race and ethnicity at both the individual and neighborhood level should be a high priority for future research.
} 
Between state dispersion in NHBA also did not change much in the Great Recession and has been reasonably stable through 2016 but exhibited a decline and then recovery in the 201718 period. Between state dispersion in NHBA in the pandemic follows the patterns for HBA closely rising sharply from May through July 2020 and then declining through March 2021 but at a level higher than pre pandemic.

Comparing the patterns of between sector and between state dispersion (Figures 8 and 11, respectively), the increasing dispersion in between sector growth rates is more persistent than the increase in dispersion in between state growth rates. While more research is needed on understanding these differences, these patterns suggest a more profound restructuring between sectors than between states. Interestingly, Buffington et al. (2021) find that the uneven impact of the pandemic on existing small businesses is more persistent between sectors than between states.

What we do not know from the public-domain BFS is how the restructuring across sectors and states are related. For example, in the locations where existing small businesses in specific sectors have been hit the hardest, are new applications surging? Alternatively, it may be that it is in the locations where existing small businesses in specific sectors have fared the best that new applications are surging. In other words, is the observed restructuring within sector/location cells are between sector/location cells? Future research using the micro data underlying the BFS can be used to investigate these issues.

\section{New Business Applications, Business and Worker Turnover}

Figure 2 makes clear the tight relationship between new business applications for likely employers (HBA) in each month and new employer business startups in the subsequent 8 
quarters. As discussed above, new employer startups play a disproportionate role in job creation, innovation, and productivity growth. This contribution is a noisy and complex one as startups are part of an ongoing creative destruction dynamic in the economy. While it is beyond the scope of this paper to explore this latter connection fully, in this section the relationship between new business applications for likely employers and indicators of business and worker turnover is explored.

For this purpose, the monthly applications for likely employers are aggregated to the quarterly frequency to enable analysis of indicators from the Business Employment Dynamics (BED). The latter provides quarterly estimates of business births and deaths (at the establishment-level). Estimates of hires, separations and job openings from Job Openings and Labor Turnover Survey (JOLTS) are also used. While JOLTS is available at the monthly level, for the analysis in this section these measures are also aggregated to the quarterly frequency to facilitate a joint analysis of the indicators from the BFS, BED and JOLTS.

Simple bivariate Vector Autoregression (VAR) are used to quantify joint dynamics. Technical details of the specifications are described in the appendix. The analysis of these dynamics is restricted to the quarterly data from 2004:3-2019:4. This restriction in this dynamic VAR analysis is for a number of related reasons. First, as is evident from Figure 1, there are dramatic fluctuations in the business applications during the COVID-19 pandemic that are unprecedented in magnitude. Second, new business applications are inherently forward looking since the BFS shows that it can take more than one year for HBA applications to yield actual new employer business startups. ${ }^{16}$ Given the potentially substantial lags, the surge in business applications in the second half of 2020 is unlikely to have its full effect on other indicators until

\footnotetext{
${ }^{16}$ This can be seen by the finding that SBF8Q exceeds SBF4Q.
} 
several quarters in the future. Given the nature of the analysis, appropriate caution is needed in making inferences about the implications of the surge in applications during the pandemic for business and worker turnover. Still the analysis in this section provides guidance about the potential future impact of the pandemic surge in applications based on historical patterns.

Figure 12 reports cumulative impulse response functions of a quarterly innovation in HBA to establishment openings and closings. ${ }^{17}$ A one standard innovation in HBA yields a substantial and significant increase in business births over the next 16 quarters (see panel A). This evidence is consistent with Figure 2. The novel insight from Figure 12 is that a one standard innovation in HBA also yields a substantial and significant increase in business deaths over the next 16 quarters (panel B). In unreported results (available upon request), there is no evidence of reverse causality. ${ }^{18}$ That is, there is no evidence that an innovation in business births or deaths yields subsequent significant changes in new business applications.

Figure 13 illustrates that distinct but related dynamics are present for hires and separations. A one standard deviation in HBA yields substantial and significant increases in hires and separations rates over the next 16 quarters. ${ }^{19}$ Figure $14(\mathrm{a})$ shows that the impact on hires is greater than the impact on separations as the net employment growth impact (hires minus

\footnotetext{
17 The mean establishment birth and death rates are about 3 percent per quarter with a standard deviation of about 0.2 .

${ }^{18}$ That is, an innovation in the business births or deaths variable yields no substantial subsequent change in HBA applications. These statements hold regardless of the Choleski ordering used in the VAR analysis. See the appendix for more detail. The orthogonalized MA representation of the impulse response functions can be given a causal interpretation. Often the causal inferences depend on the Choleski ordering but not in this case.

${ }^{19}$ The mean hires and separations rates are about 10.7 and 10.5 percent per quarter, respectively. The corresponding standard deviations are about 0.9 and 0.8 percent, respectively. For the net employment growth rate (from hires minus separations) the mean is 0.2 per quarter with a standard deviation of 0.5 . The job openings rate has a mean of about 10 percent per quarter with a standard deviation of 2.5 .
} 
separations from JOLTS) is positive. There is also a substantial and significant impact on job openings over the next 16 quarters (Figure 14b). ${ }^{20}$

The results in this subsection are suggestive and call for further research. Figures 12 through 14 do not provide guidance on the mechanisms underlying these patterns but highlight the close connection between new business applications and business and worker turnover. For example, the surge in business deaths following an innovation in new applications may reflect creative destruction forces at work or alternatively but relatedly the propensity of many new businesses to exit. More generally it may be that new business applications react quickly to current or expected changes in economic conditions that are harbingers of indicators of business and worker turnover. Further evidence and discussion of these issues is provided in Asturias et al. (2021). This latter research provides evidence that an innovation in the growth in HBA yields a substantial and persistent increase in non-farm payroll employment growth. This latter finding is consistent with the implied larger impact of HBA on hires vs. separations discussed above.

\section{COVID-19 Economic Stimulus Policies and Entrepreneurship}

Given the importance of the Paycheck Protection Program (PPP) for existing small businesses (75\% of existing small businesses in the SBPS report receiving PPP assistance), a natural question to ask is whether the PPP impacted new business applications. ${ }^{21}$ This is a complex question that requires more research in part because the PPP and other fiscal stimulative programs may have impacted new business formation indirectly via the impact on the overall

\footnotetext{
${ }^{20}$ Unreported results available upon request show little evidence of reverse causality for hires, separations, net employment growth or job openings.

${ }^{21}$ See also Buffington et al. (2021) for a discussion of this issue.
} 
economic outlook. Alternatively, economic theory implies (see, Acemoglu et al. (2018)), support for incumbent businesses can have a negative impact on business formation.

The key to thinking about this question is that the PPP program is designed to provide support to existing businesses. Applicants for PPP must have been in business by February 2020 with the loan application requiring documentation of business activity pre-pandemic. This implies that employer businesses that received a PPP loan already had an EIN in February 2020 well before the surge in new business applications. Most of the PPP loans went to employer businesses. ${ }^{22}$ Holding the state of aggregate economy fixed, this support for existing small businesses is if anything likely to have dampened the incentives for starting new employer businesses. Viewed from this perspective, the surge in applications for likely employer businesses is arguably not because of, but despite, the PPP program.

Of course, the state of the economy has been anything but fixed. In considering these issues, the discussion of the cyclical patterns of new business applications and business formation in section III.C is relevant. Davis and Haltiwanger (2019) highlight that all economic downturns since the early 1980s have exhibited a decline in employer business startups relative to trend. From this perspective, the pandemic would have been expected to lead to a decline in applications for new employers. However, given that self-employment has a countercyclical component, the pandemic would have been expected to yield an increase in nonemployer activity and in turn applications for likely nonemployers. To the extent the CARES act dampened the adverse effect of the pandemic on the economy, the cyclical impact on new business formation

\footnotetext{
${ }^{22}$ About $1 / 7$ of the recipients of PPP were nonemployers as of February 2020. Many of these likely also had an EIN. An EIN is required for nonemployer corporations and partnerships. Also, many sole proprietor nonemployers have an EIN as this facilitates doing business with other businesses and an EIN is required for having a business bank account. It is possible that some of the relatively small fraction of nonemployer, sole proprietor PPP loan recipients were induced to apply for an EIN as part of the PPP program. See appendix B for further discussion.
} 
would have been expected to have been dampened. Moreover, as discussed above, the PPP component of the CARES act by subsidizing incumbents may have dampened new applications for likely employers. Other components of the CARES act (e.g., direct payments to households) may have helped boost the incentives to start new businesses. ${ }^{23}$

This discussion helps highlight why the surge in applications for both likely employers and nonemployers is at least ex ante surprising. As it has become clear that the pandemic is leading to both short run and potentially longer run restructuring of the U.S. economy, this surge is less surprising.

\section{Concluding Remarks}

The surge in applications for new businesses in the pandemic has been large and distinct. The total number of applications in 2020 is the highest by far compared to all years for which the data have been available. The increase from 2019 to 2020 in total applications exceeds 20 percent which is double the growth rate in any other year. The increase is in applications for both likely employers and nonemployers. All of the increase in 2020 is accounted for by a surge in applications in the second half of 2020. This surge in applications has continued through May 2021. Based on historical patterns, this surge in applications should result in a surge in new employer and nonemployer businesses. The increase in new employer businesses should be within four to eight quarters of the date of the applications based upon historical patterns.

The surge in new business applications has been uneven across sectors. Ten 3-digit industries out of about 100 3-digit industries account for 75\% of the surge. Dominant industries include Nonstore Retail (alone accounting for 33\% of the surge), Personal Services, Professional, Scientific and Technical Services, Administrative and Support Services, Truck Transportation,

\footnotetext{
${ }^{23}$ Fazio et al. (2021) offer some evidence in support of this hypothesis.
} 
and Accommodation and Food Services. Given that existing small businesses in Retail Trade and Accommodation and Food Services have suffered especially large declines in the pandemic, these patterns are consistent with restructuring induced by the pandemic. As the economy recovers from the pandemic, an open question is the extent to which the increases in remote/telework activity observed during the pandemic will persist. The extent to which these changes "stick" is likely to vary across types of businesses and locations. The shift towards ecommerce is likely to stick as this reflects a pre-pandemic trend. Viewed from this perspective, the pandemic may be accelerating ongoing trends and the surge in business applications is part of this process.

Does this surge in new business applications imply there will be a surge in job creation, innovation, and productivity growth over the next few years? Obviously, this is an open question but in considering these possibilities several factors are important to consider. First, basic facts about new businesses (see, Haltiwanger, Jarmin and Miranda 2013 and Decker et al. (2014)) highlight that most new employer businesses fail within the first five years after entry and conditional on survival, most do not grow. A relatively small fraction of young businesses grow very rapidly and it is these high growth firms that are especially important for job creation that persists, innovation and productivity growth. The analysis in this paper shows that the prepandemic a surge in new business applications has yielded substantial and significant increases in indicators of both business and worker turnover over the subsequent four years. It remains to be seen whether similar patterns will apply in the next few years.

The surge in applications for likely nonemployers is also of interest as an indicator of the changing structure of the economy. The number of nonemployer businesses has been on an upward trend over the last 15 years or so with rapid acceleration in the post-2010 period. As 
discussed in Abraham et al. (2021), this reflects an increase in the gig economy including and especially the ridesharing industries. The evidence presented in Abraham et al. (2021) (and references therein) highlight that much of nonemployer activity reflects supplemental and stopgap activity.

The surge in applications for likely nonemployers thus may reflect at least in part an acceleration of pre-pandemic trends. However, several factors suggest the surge is more complicated. For one, the surge in applications for likely nonemployers are for those applying for EINs. Most of the nonemployers in the ridesharing industry are sole proprietors that are not required to have an EIN. In addition, the surge in applications for likely nonemployers are in sectors that reflect promoting remote activity such as Nonstore retailers. Just as for new employer startups, an open question is whether new nonemployers also will "stick”. A closely related question is whether the new nonemployers business activity will mostly be stopgap or supplemental as in the past. Or alternatively are we seeing an increase in the share of individuals where nonemployer activity is the primary or only source of work activity?

Finally, the surge in new business applications raises a variety of important measurement questions and challenges. For one, the high frequency traditional statistical series such as the BLS monthly payroll report rely on imputing aggregate growth based upon survey respondents that provide reports in consecutive months. ${ }^{24}$ An adjustment is made for the impact of births and deaths using a birth-death model. Benchmark revisions are made annually based upon comprehensive administrative data. An open question is whether this surge in applications will imply large benchmark adjustments as the birth-death model is based on historical relationships that do not hold in the pandemic. Second, interpreting the impact of the surge in applications is

\footnotetext{
${ }^{24}$ This limitation is shared by many high frequency economic indicator surveys.
} 
hampered by limitations in other key related series. To understand the implications of business entry variation over time, industry and location, evidence on business exit is also needed. As highlighted by Crane et al. (2020), official statistical agency reports on business closures emerge only slowly given the relatively slow processing of key administrative data at Census (e.g., payroll tax reports) and BLS (e.g., ES-202 employment reports as part of the QCEW program). Business closure data from these sources for all of 2020 will begin to become available in published statistics in late 2021. Relatedly reports on the outcomes of existing young and small businesses by sector and location depend on this same administrative data. This implies that understanding where the observed fluctuations in the BFS fit into these outcomes will take some time to sort out. Novel high frequency surveys like the SBPS help fill in the gaps but have some limitations. As noted by Buffington et al. (2021), the SBPS is more informative about continuing small businesses than business closures (as survey non-response is inherently higher for businesses that have ceased operations). More research is needed to help develop these important measures of business deaths. 


\section{References}

Abraham, Katharine G., John C. Haltiwanger, Kristin Sandusky, and James R. Spletzer (2021) "Measuring the Gig Economy Current Knowledge and Open Issues" in NBER/CRIW Conference Volume on Measuring and Accounting for Innovation in the $21^{\text {st }}$ Century, (forthcoming).

Acemoglu, Daron, Ufuk Akcigit, Nicholas Bloom, and William. R. Kerr (2018) "Innovation, Reallocation and Growth," American Economic Review, 108, 3450-3491.

Alon, Titan, David Berger, R. Dent, and Benjamin. Pugsley (2018) "Older and slower: The startup deficit's lasting effects on aggregate productivity growth," Journal of Monetary Economics, 93, 68-85.

Asturias, Jose, Emin Dinlersoz, John Haltiwanger and Rebecca Hutchinson. (2021). "Business Applications as Economic Indicators,” Center for Economic Studies Working Paper, CES WP-21-09.

Bayard, Kimberly, Emin Dinlersoz, Timothy Dunne, John Haltiwanger, Javier Miranda, and John Stevens. (2018). "Early-Stage Business Formation: An Analysis of Applications for Employer Identification Numbers,” NBER Working Paper, 24364.

Buffington, Catherine, Daniel Chapman, Emin Dinlersoz, Lucia Foster, and John Haltiwanger (2021), "High Frequency Business Dynamics in the United States During the COVID-19 Pandemic,” mimeo.

Crane, Leland D., Ryan A. Decker, Aaron Flaaen, Adrian Hamins-Puertolas, and Christopher Kurz (2021). "Finance and Economics Discussion Series 2020-089r1. Washington: Board of Governors of the Federal Reserve System, https://doi.org/10.17016/FEDS.2020.089r1.

Davis, Steven, and John Haltiwanger (1999), “Gross Job Flows” Handbook of Labor Economics, Volumes 3 and 4, edited by Orley Ashenfelter and David Card, 2711-2805.

Davis, Steven, John Haltiwanger, C.J. Krizan, Ron Jarmin, Javier Miranda, Al Nucci, and Kristin Sandusky (2009), "Measuring the Dynamics of Young and Small Businesses: Integrating the Employer and Non-Employer Businesses," in Producer Dynamics: New Evidence from Micro Data, (Dunne, Jensen and Roberts, eds.) NBER/University of Chicago Press, 329-366.

Davis, Steven, and John Haltiwanger (2019). “Dynamism Diminished: The Role of Housing Markets and Credit Conditions” NBER Working Paper No. 25466, January.

Decker, Ryan A., John Haltiwanger, Ron S. Jarmin, and Javier Miranda (2016) "Where has all the skewness gone? The decline in high-growth (young) firms in the US," European Economic Review, 86, 4-23. 
Decker, Ryan A., John Haltiwanger, Ron S. Jarmin, and Javier Miranda (2020) "Changing Business Dynamism and Productivity: Shocks vs. Responsiveness," American Economic Review, 110, 3952-3990.

Dinlersoz, Emin, Timothy Dunne, John Haltiwanger, and Veronika Penciakova (2021), “Business Formation: A Tale of Two Recessions,” AEA Papers and Proceedings. (forthcoming).

Fairlie, Robert (2020), “The impact of COVID-19 on small business owners: Evidence from the first 3 months after widespread social-distancing restrictions” Journal of Economics and Management Strategy, 1-14.

Fazio, Catherine, Jorge Guzman, Yupeng Liu, and Scott Stern (2021), “How is COVID Changing the Geography of Entrepreneurship? Evidence from the Startup Cartography Project," mimeo.

Fort, Teresa, John Haltiwanger, Ron Jarmin and Javier Miranda (2014), "How Firms Respond to Business Cycles: The Role of Firm Age and Firm Size,” IMF Economic Review, 520-559.

Foster, Lucia, Cheryl Grim, John Haltiwanger, and Zoltan Wolf. 2021. "Innovation, Productivity Dispersion, and Productivity Growth.” In Measuring and Accounting for Innovation in the $21^{\text {st }}$ Century, ed. Carol Corrado, Jonathan Haskel, Javier Miranda, and Daniel Sichel. Chicago: University of Chicago Press (forthcoming).

Gort, Michael and Steven Klepper. 1982. "Time Paths in the Diffusion of Product Innovations,” The Economic Journal, Vol. 92, no. 367 (Sept.), 630-53.

Guzman, Jorge, and Scott Stern. 2020. "The State of American Entrepreneurship: New Estimates of the Quantity and Quality of Entrepreneurship for 32 US States, 1988-2014." American Economic Journal: Economic Policy, 12 (4): 212-43.

Haltiwanger, John, Ron S. Jarmin, and Javier Miranda (2013) "Who creates jobs? Small versus large versus young," Review of Economics and Statistics, 95(2), 347-361.

Haltiwanger, John and Lea Rendell (2021) “Tracking Entrepreneurship in the U.S.: Survey vs. Administrative Data” (mimeo), in progress.

Jovanovic, Boyan. 1982. "Selection and the Evolution of Industry." Econometrica 50 (May): 649-70.

Pugsley, Benjamin. W., Petr Sedlacek, and Vincent Sterk (2018) “The Nature of Firm Growth," Discussion paper, CEPR Discussion Paper No. DP12670. 
Figure 1. BFS Monthly Applications

A. BFS applications 2004:m7-2021:4

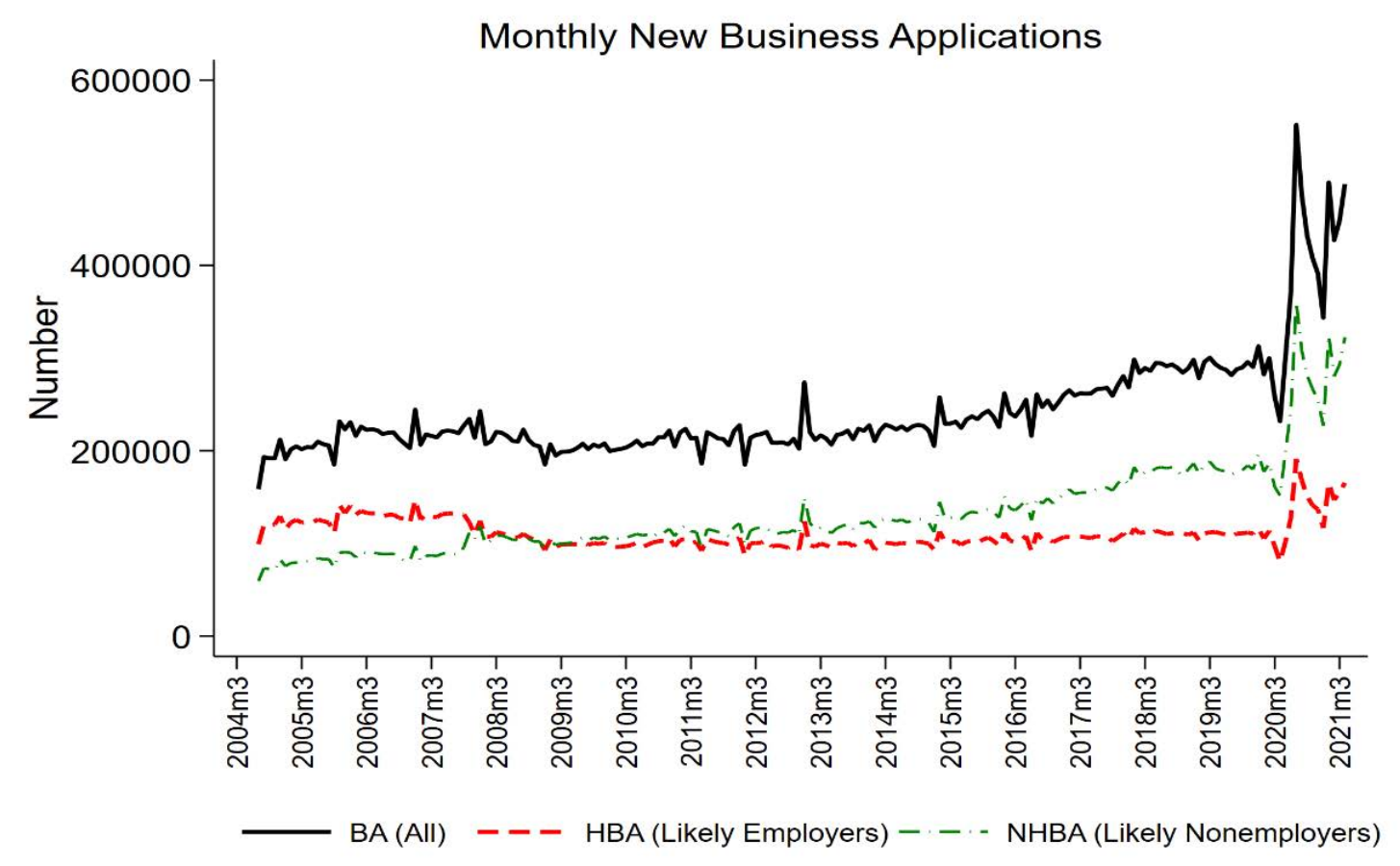

B. BFS applications 2019:m1-2021:m4

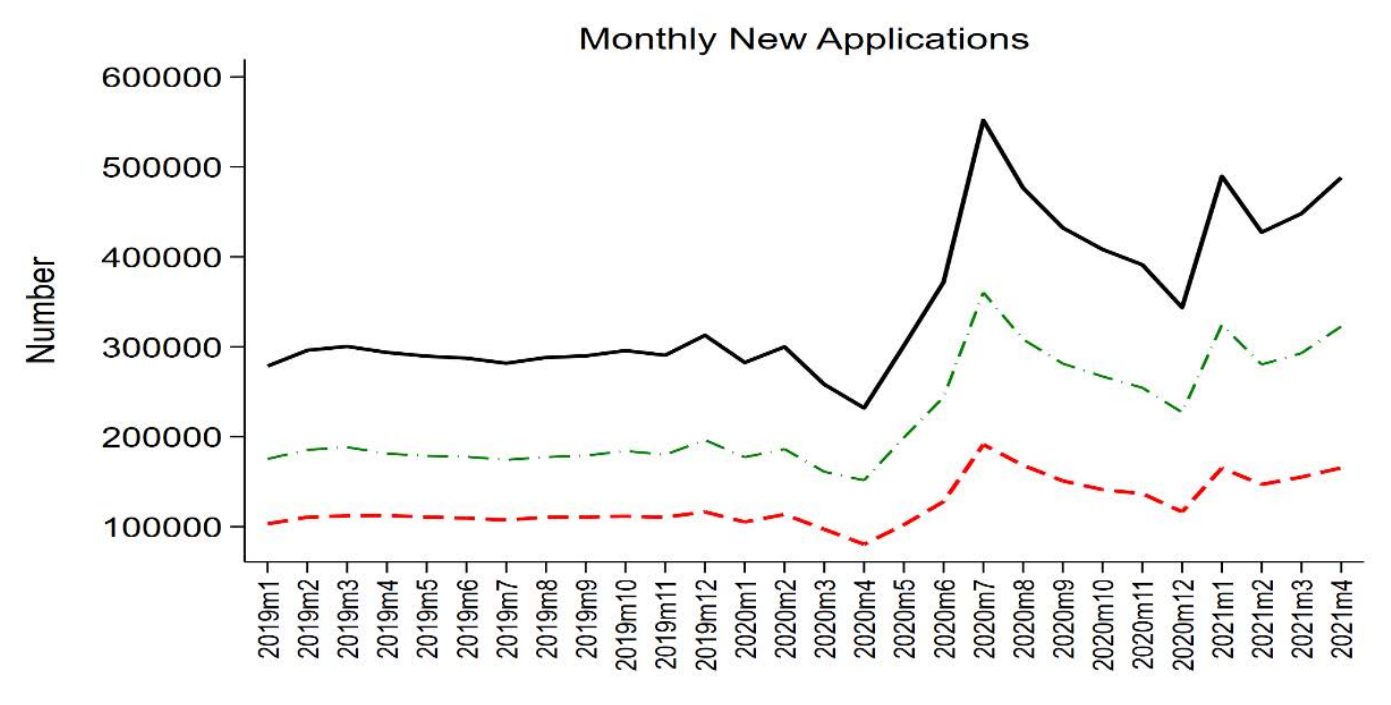

Notes: Source: BFS. BA=All business applications. HBA=High Propensity Applications (likely employers). NHBA=BA-HBA (likely nonemployers) 
Figure 2. Monthly Applications for Likely Employers and New Employer Startups

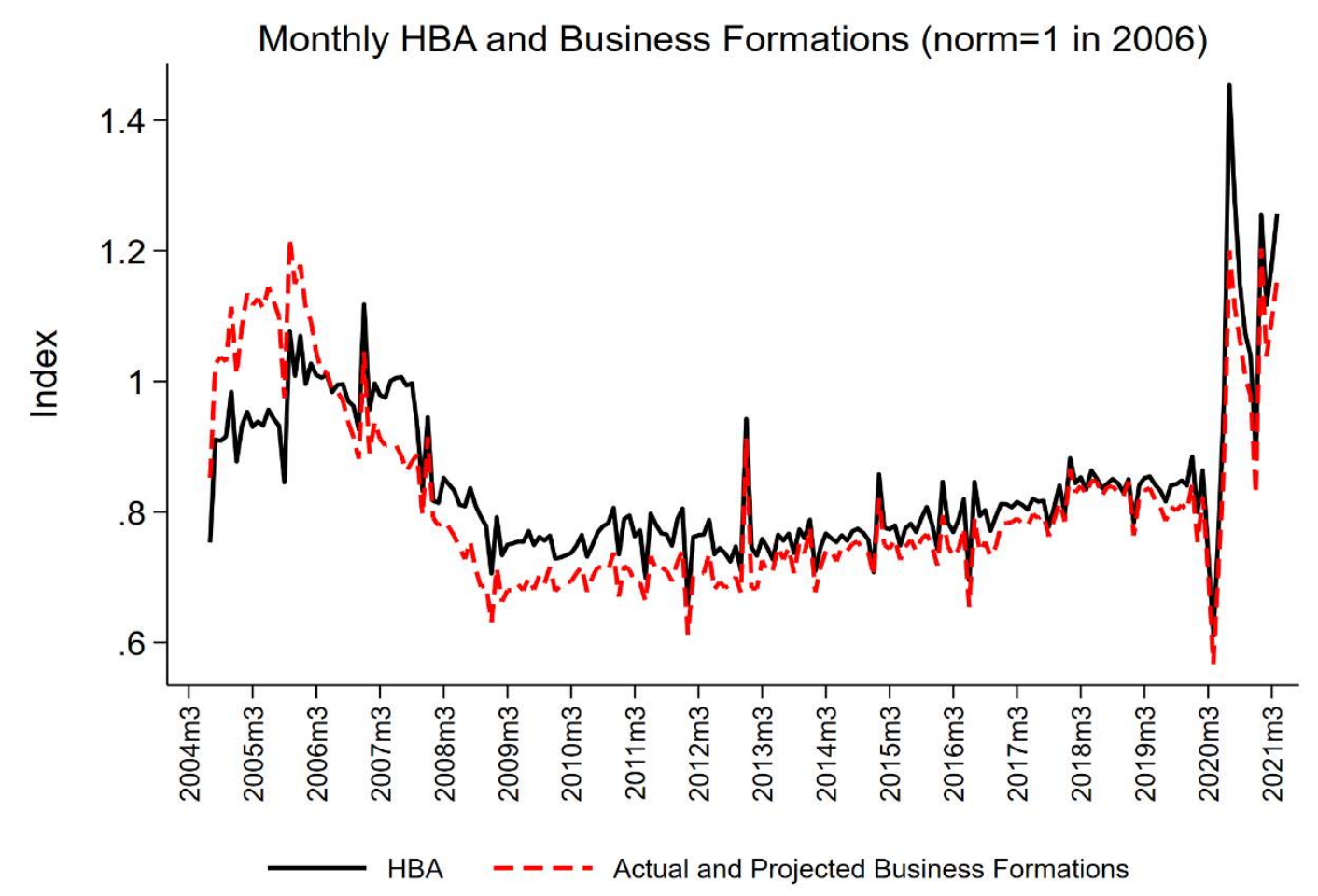

Notes: Source: BFS. HBA=High Propensity Applications. Actual and projected transitions = SBF8Q. Actual transitions through 2018. 
Figure 3. The Relationship between NHBA and Nonemployers

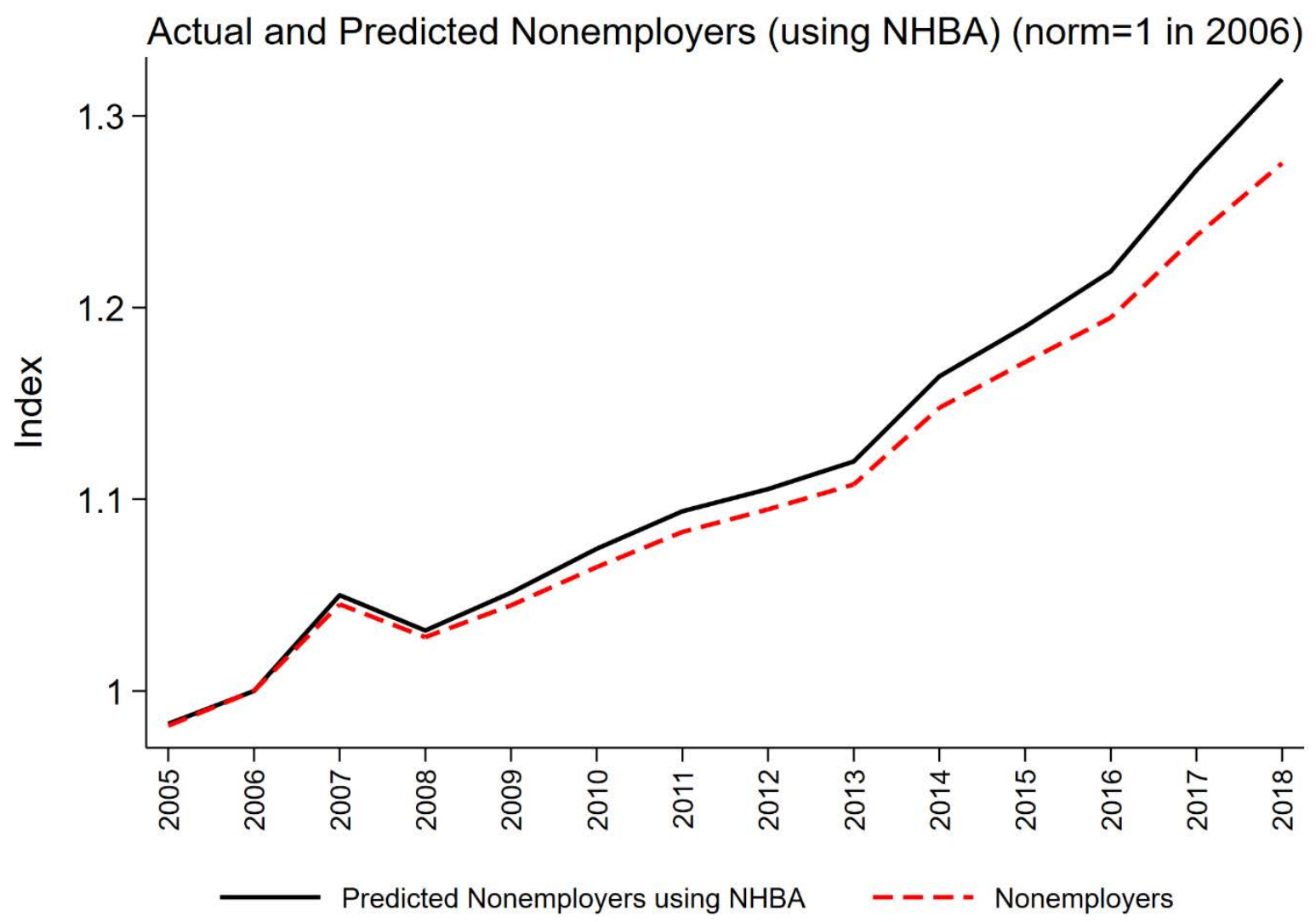

Note: Source: BFS and NES statistics from Census. Predicted nonemployers using NHBA uses exit rates from nonemployers from Davis et al. (2009) and entry rates based on NHBA. 
Figure 4. Comparison in Patterns of Business Applications Between COVID-19 and Great Recession.

A. COVID-19

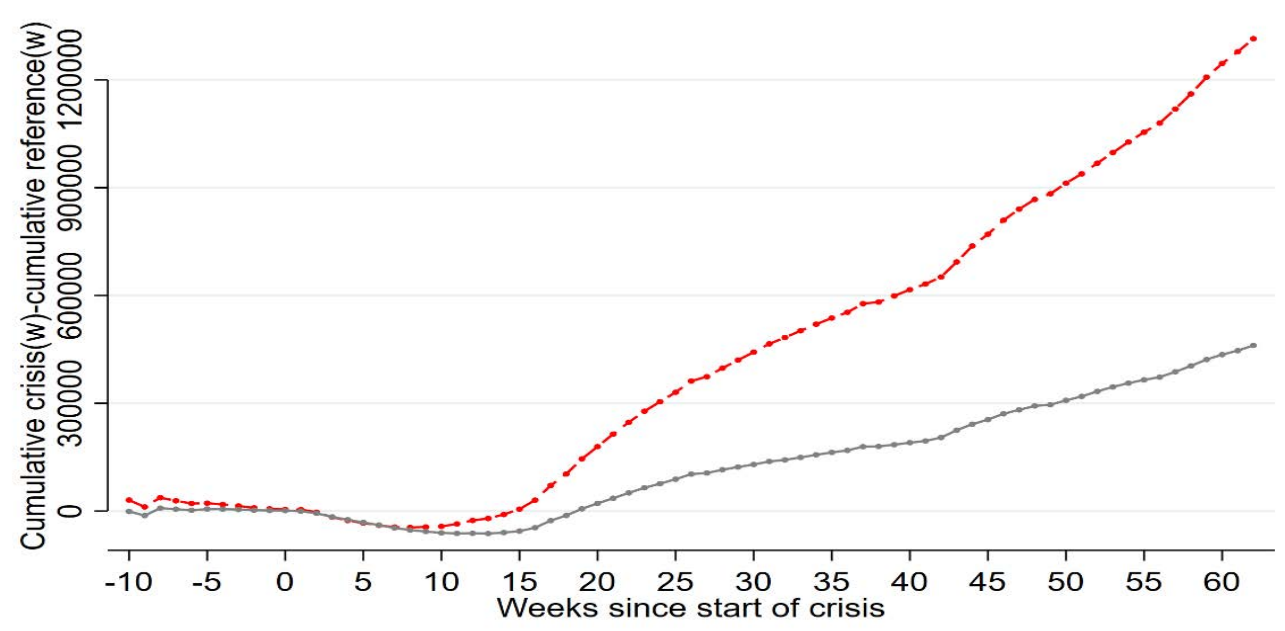

- - - - Likely Nonemployers

Likely Employers

Applications for New Businesses from the Weekly BFS

B. Great Recession

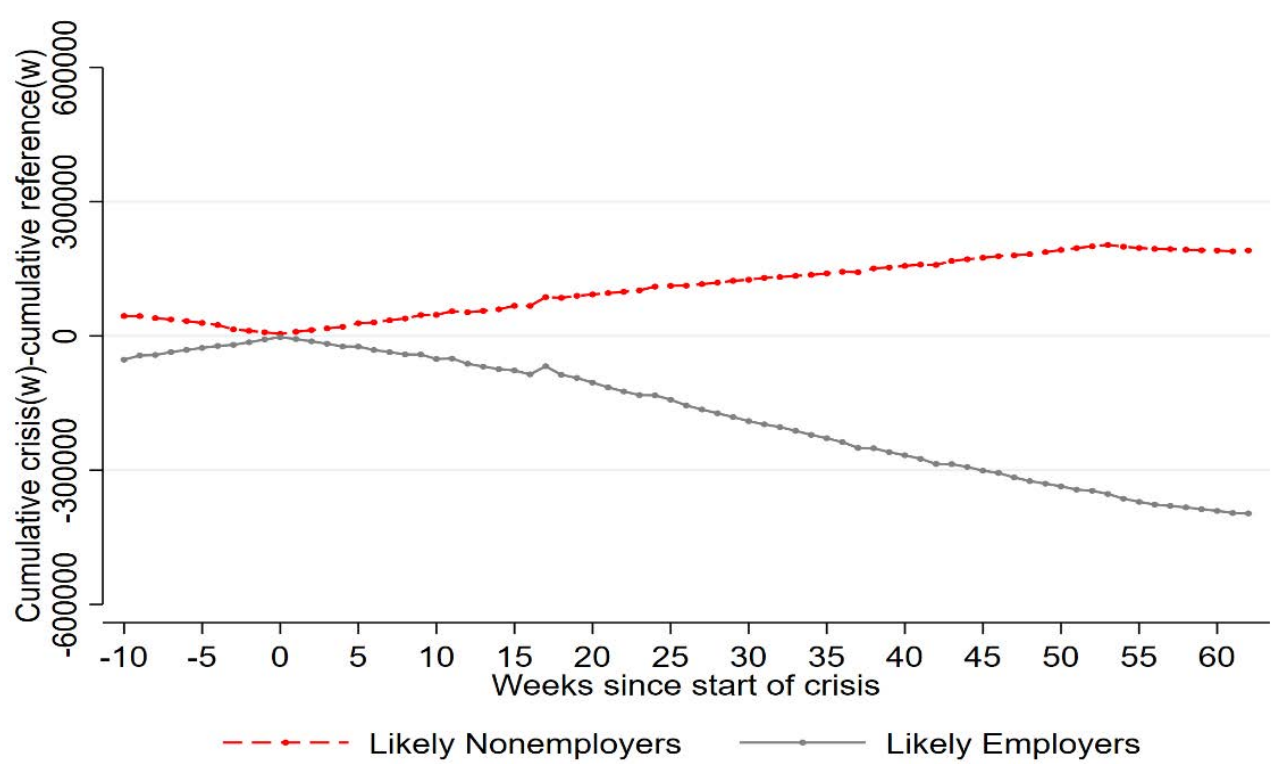

Applications for New Businesses from the Weekly BFS

Notes: Source (BFS Weekly through May 15, 2021). Week 0 for COVID-19 Recession in crisis period is week ending March 7, 2020 (referred to as week 10 in BFS weekly calendar). Week 0 for reference period for COVID-19 Recession analysis is the equivalent week 10 in 2018. Week 0 for Great Recession in crisis period is week ending September 13, 2008 (referred to as week 37 in BFS weekly calendar). Week 0 for reference period for Great Recession analysis is the equivalent week 37 in 2006. 
Figure 5. New Business Applications for Likely Employers (HBA), Selected Sectors

A. $2004: m 7-2021: 4$

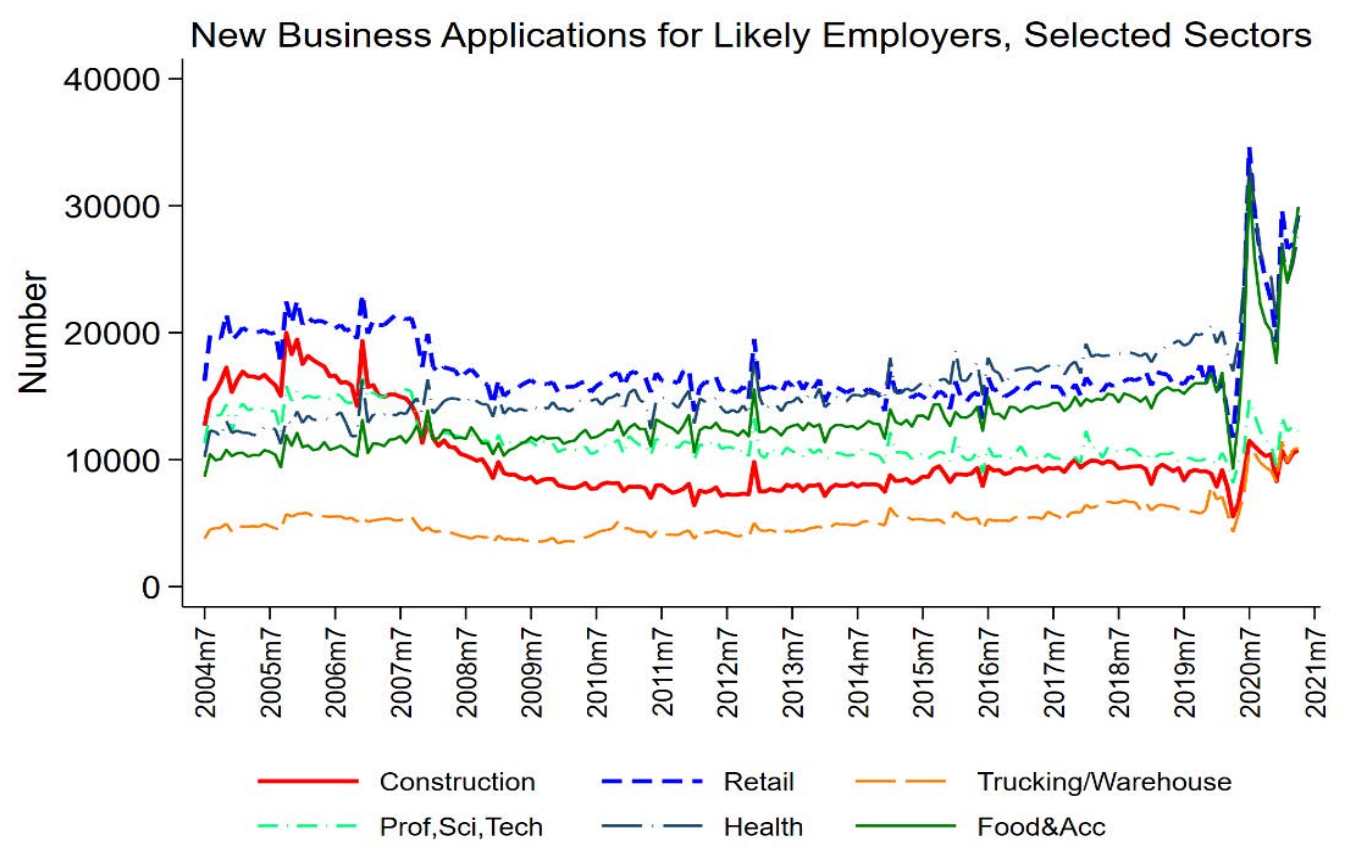

B. 2019:m1-2021:4

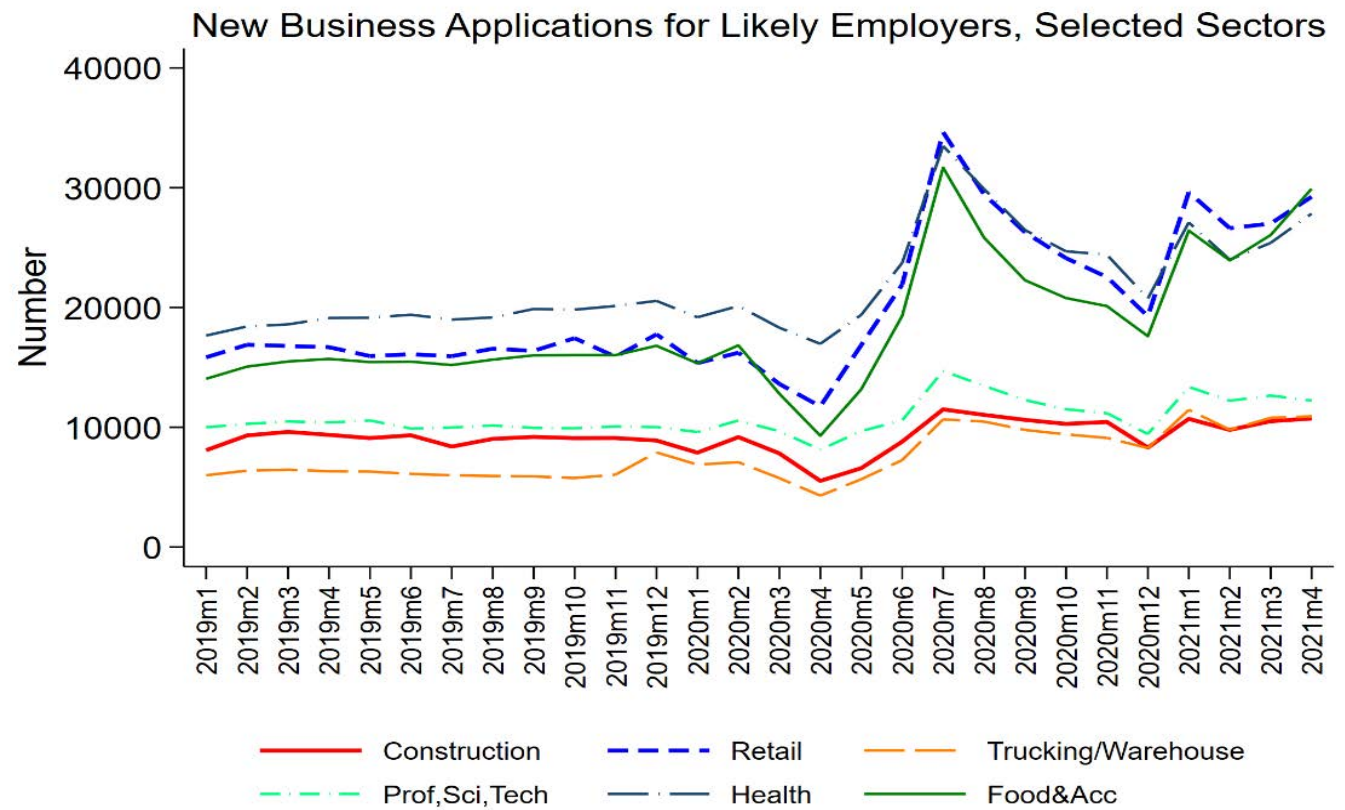

Notes: Source: BFS. 
Figure 6. New Business Applications for Likely Nonemployers (NHBA), Selected Sectors

A. 2004:m7-2021:m4

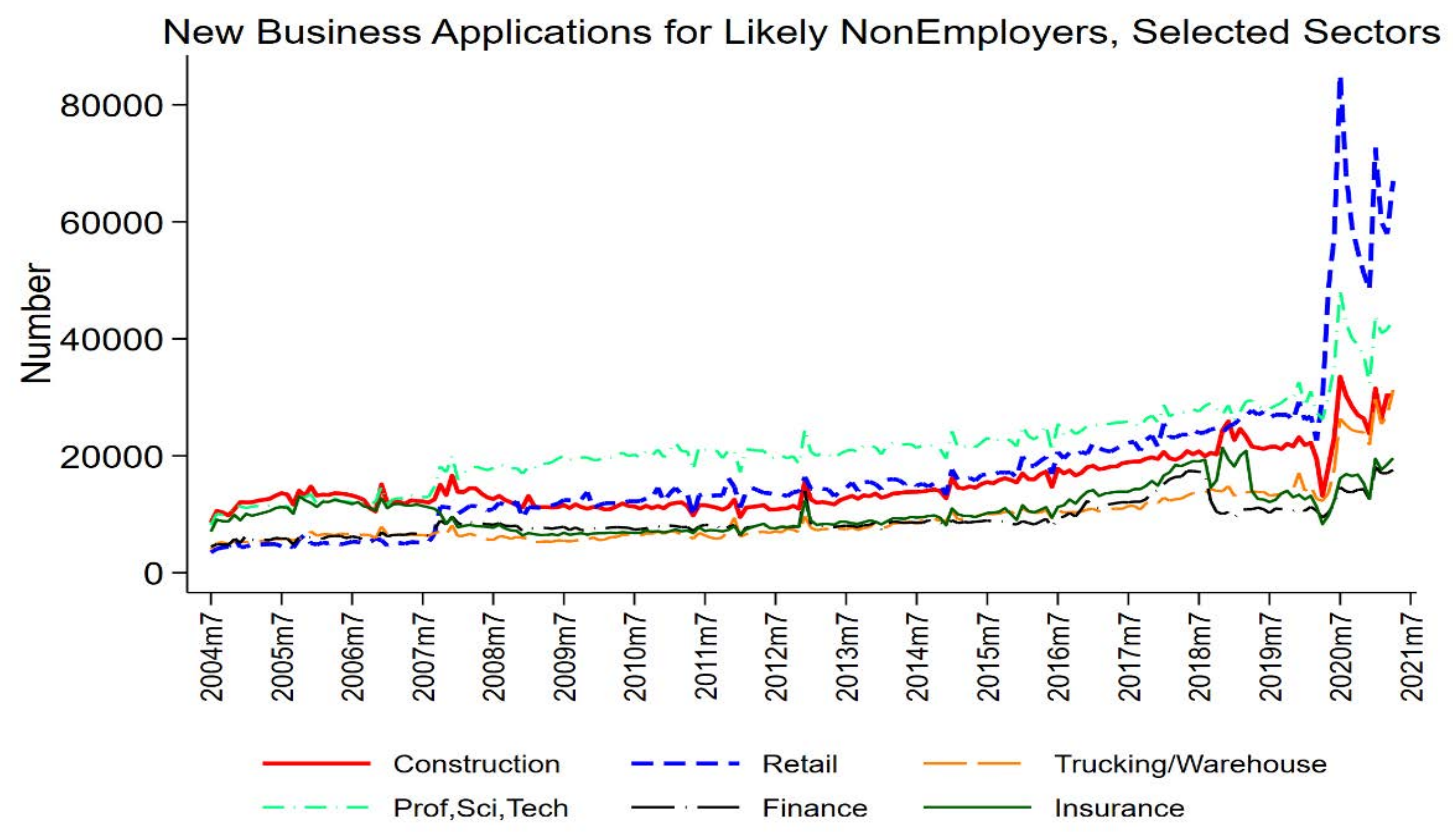

B. 2019:m1-2021:m4

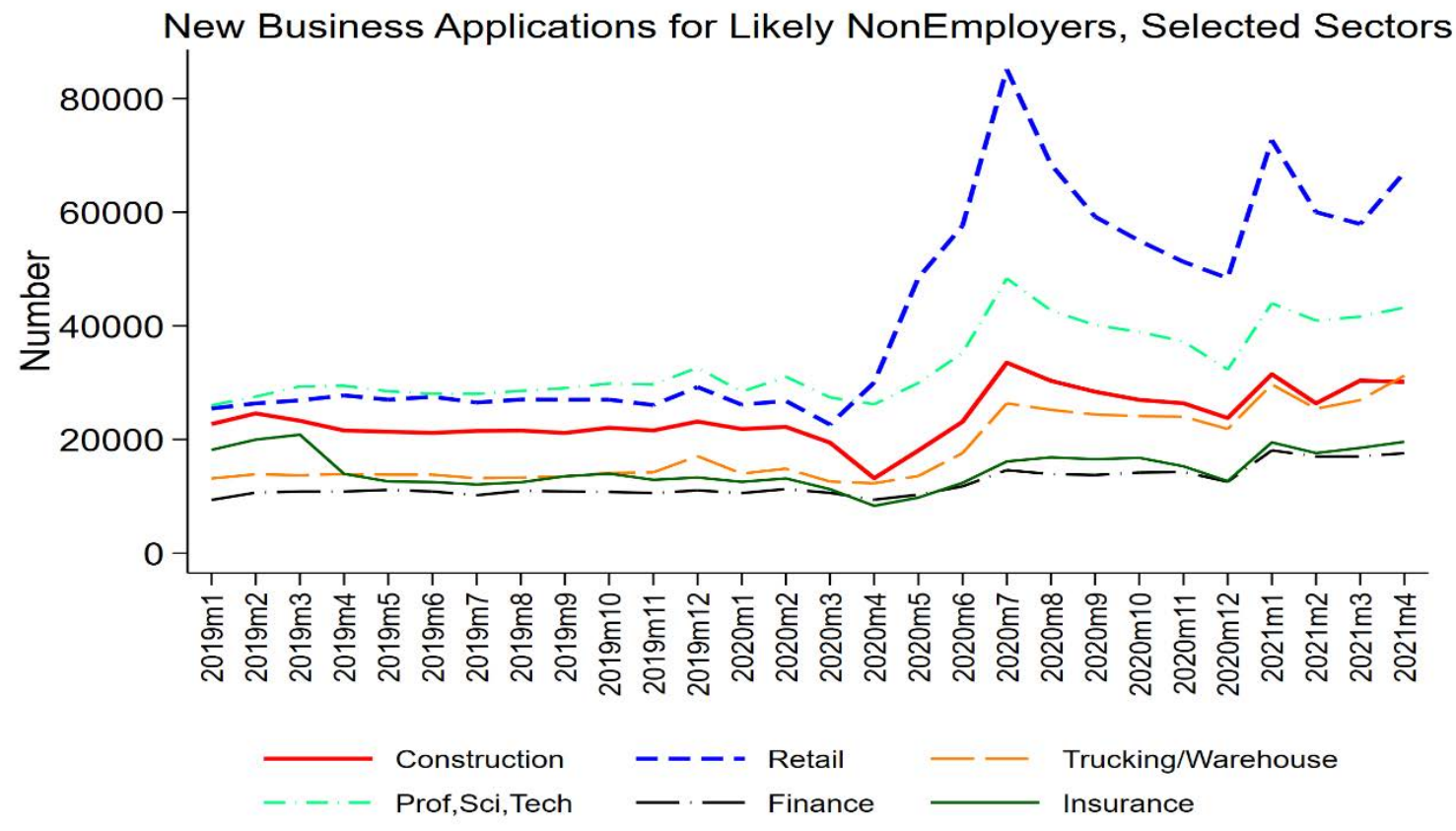

Source: BFS 


\section{Figure 7. Changing Sectoral Composition of Applications Between 2019 and 2020}

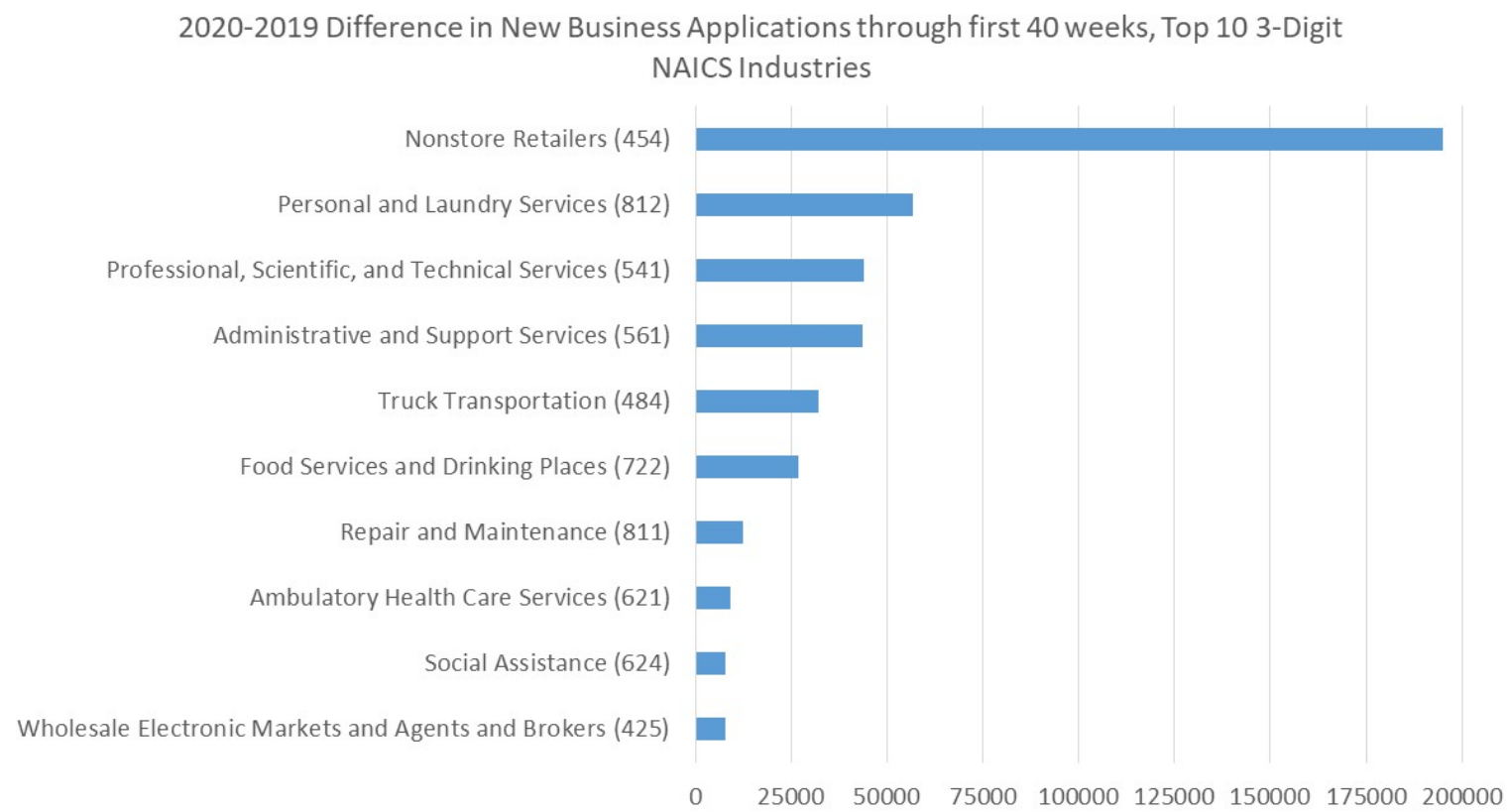

Source: Census Bureau, Business Formation Statistics. NAICS 3-digit code in parentheses. 
Figure 8. Dispersion in Between Sector Net Growth Rates for Likely Employers (HBA) and Nonemployers (NHBA)

A. 2005:m7-2021:m4

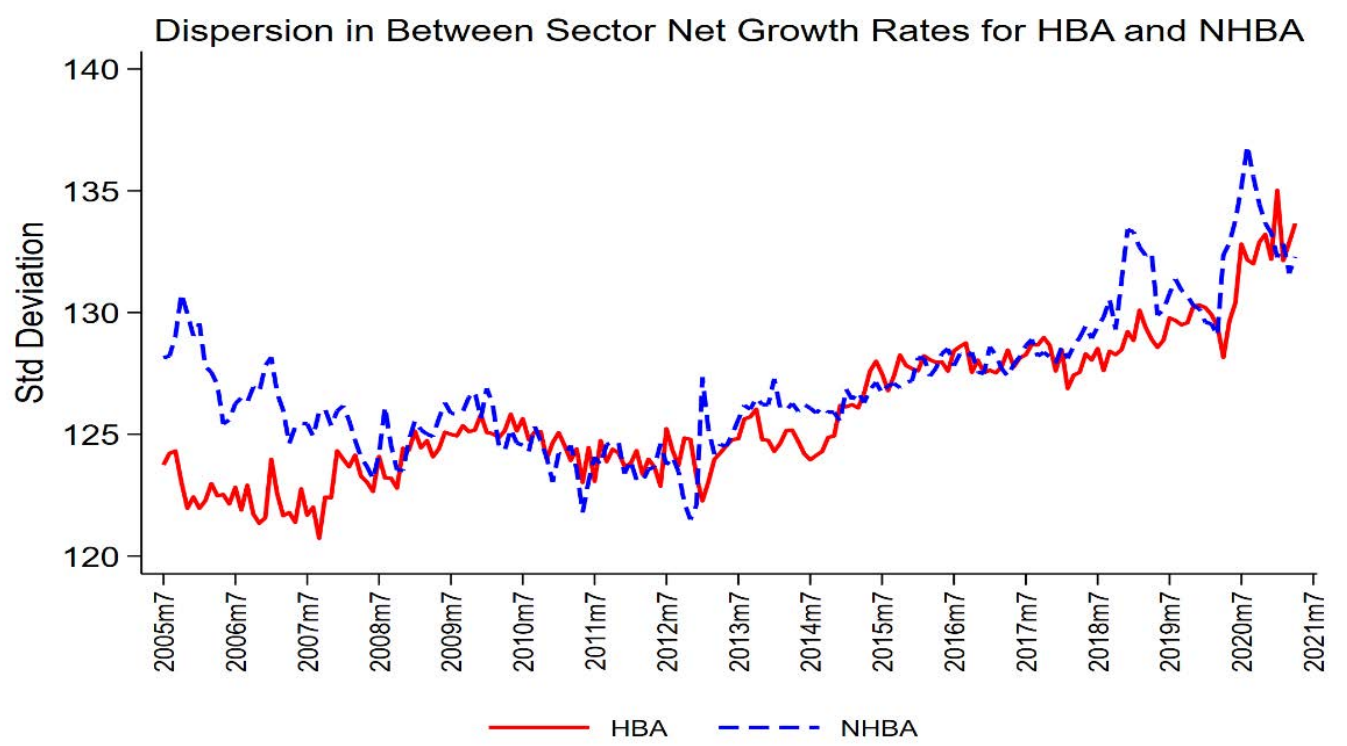

B. 2019:m1-2021:m4

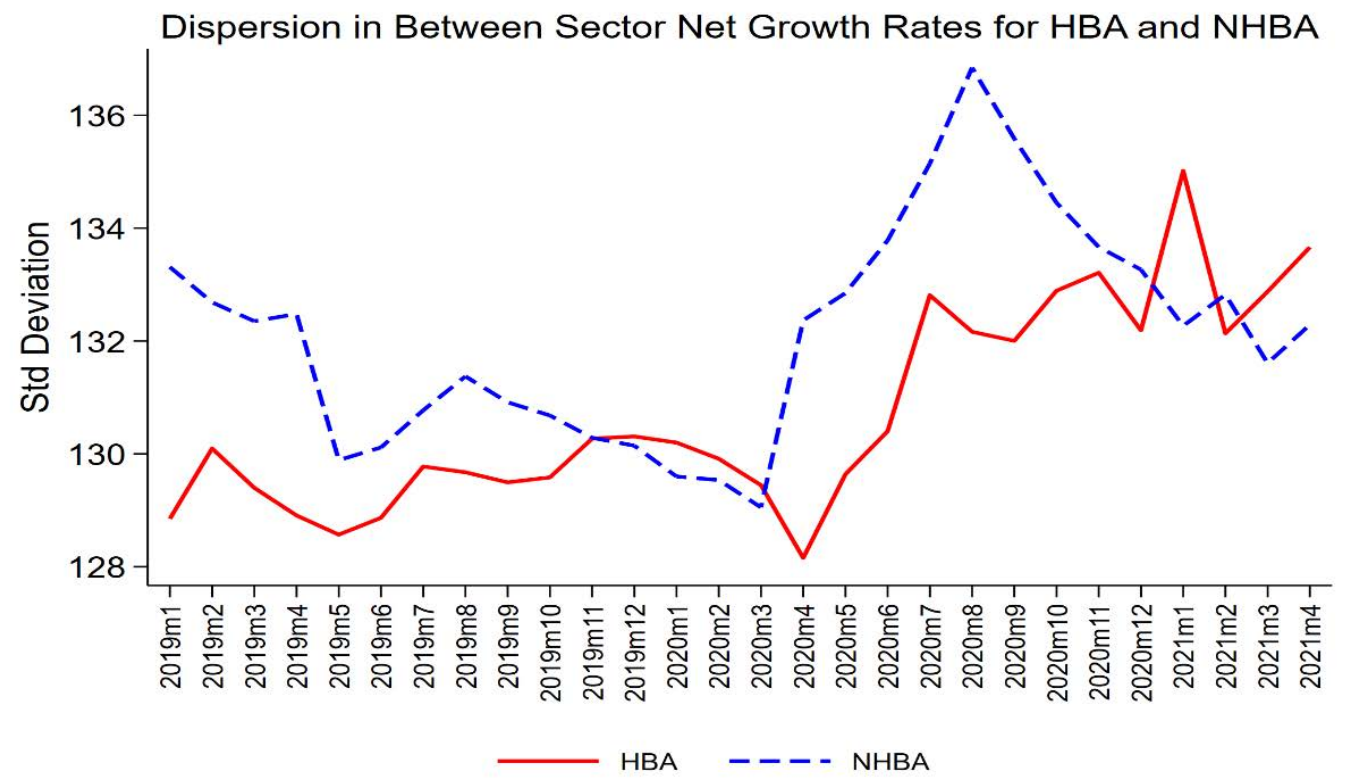

Notes: Source: BFS. Standard deviation of $\mathrm{Y} / \mathrm{Y}$ monthly growth rates across 2-digit NAICS sectors. 
Figure 9. New Business Applications for Likely Employers (HBA), Selected States

A. 2004:m7-2021:m4

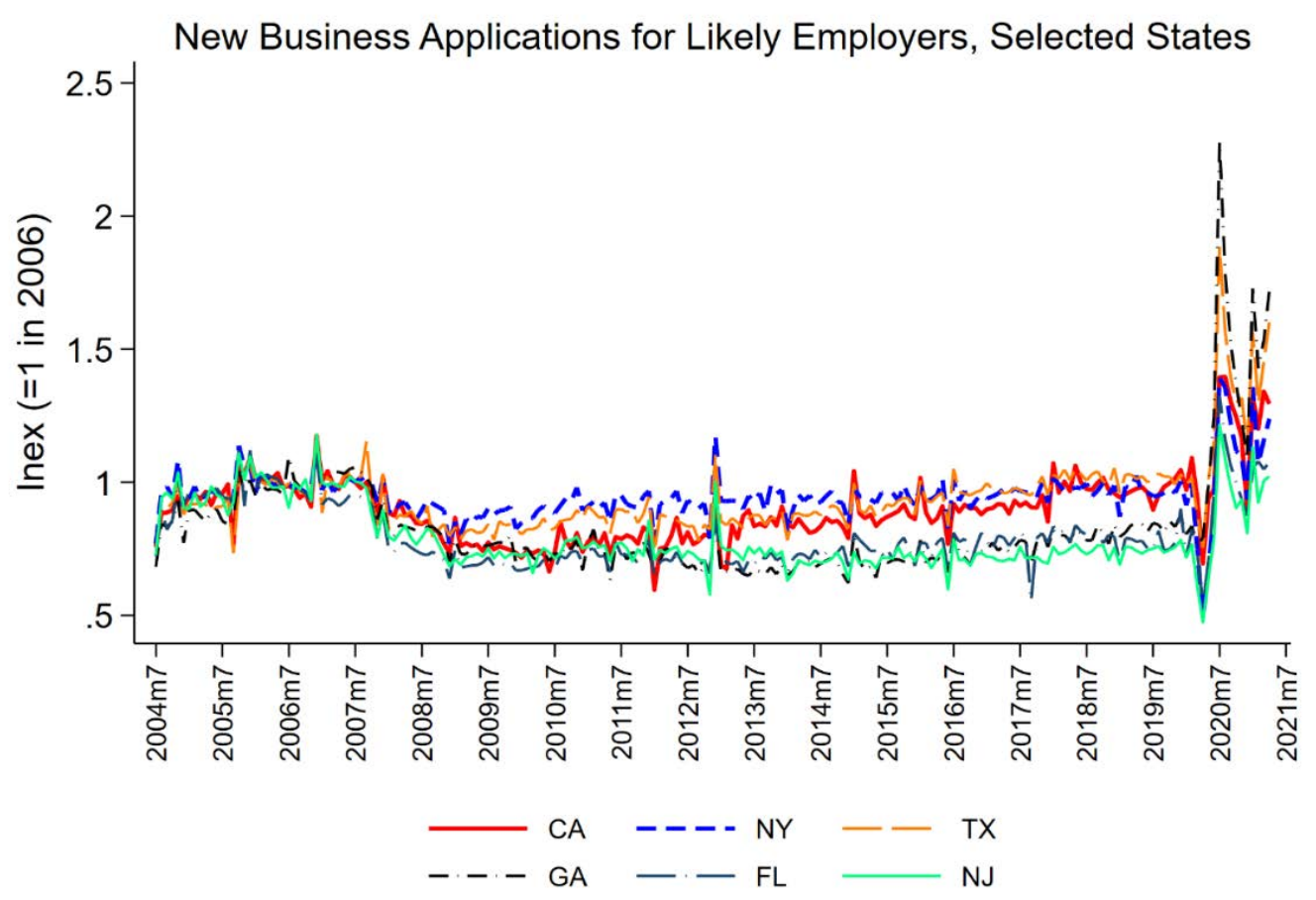

B. 2019:m1-2021:m4
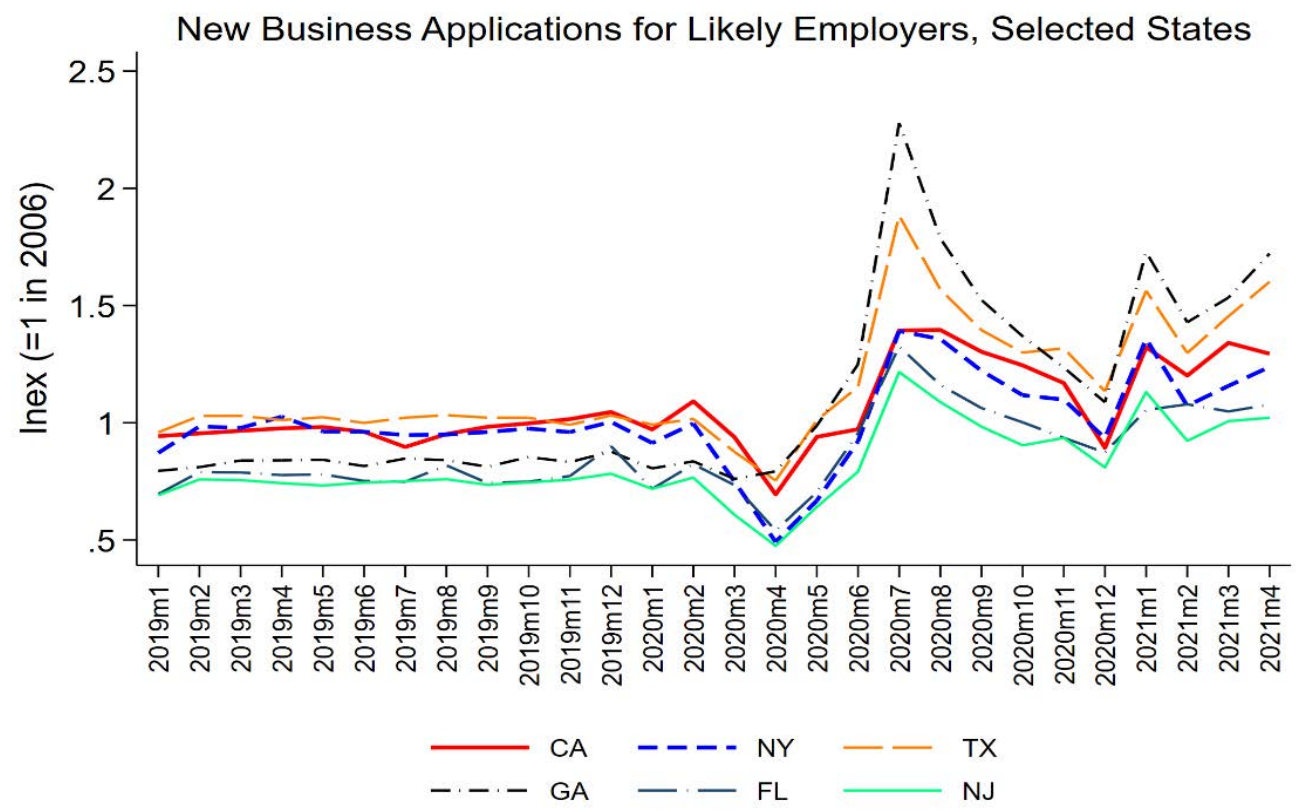

Source: BFS. 
Figure 10. New Business Applications for Likely Nonemployers (NHBA), Selected States

A. 2004:m7-2021:m4

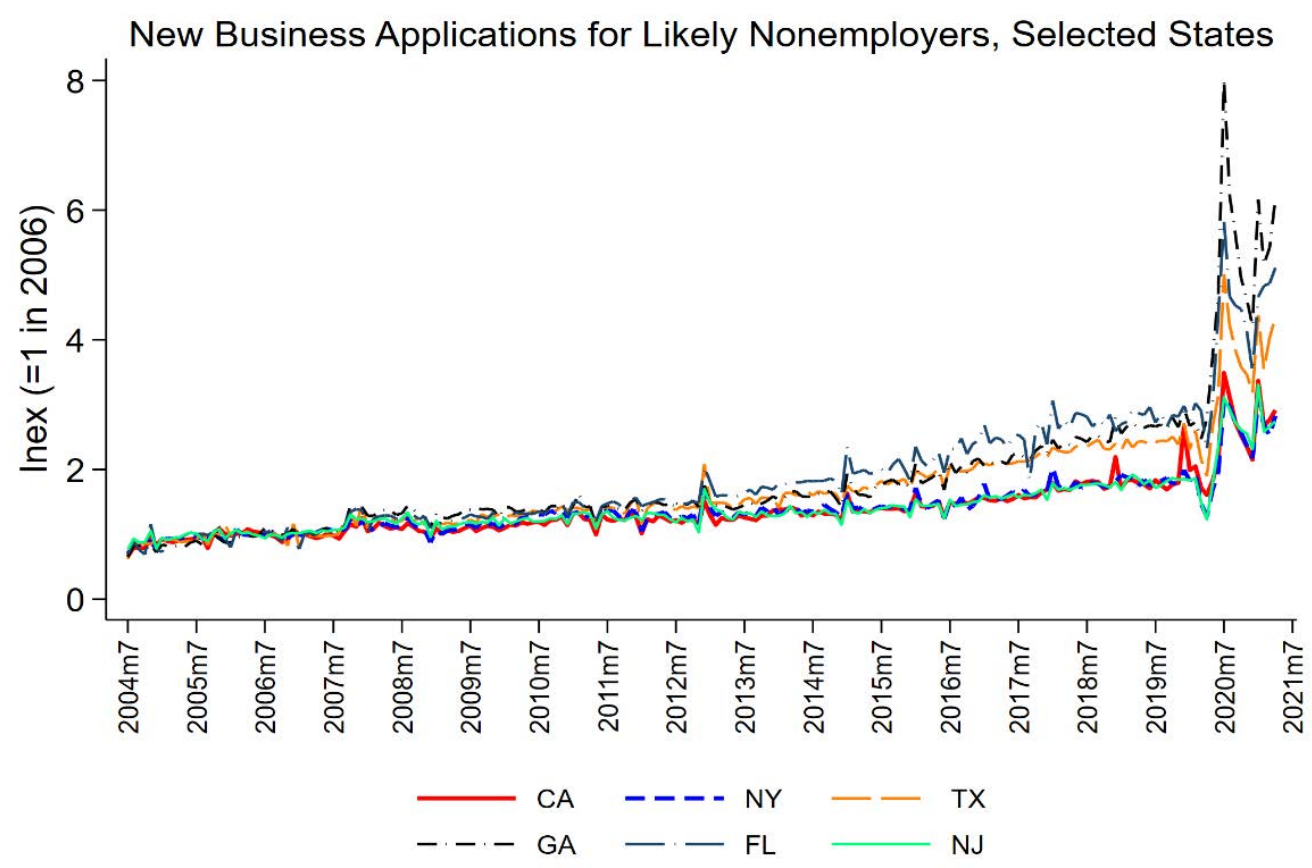

B. 2019:m1-2021:m4
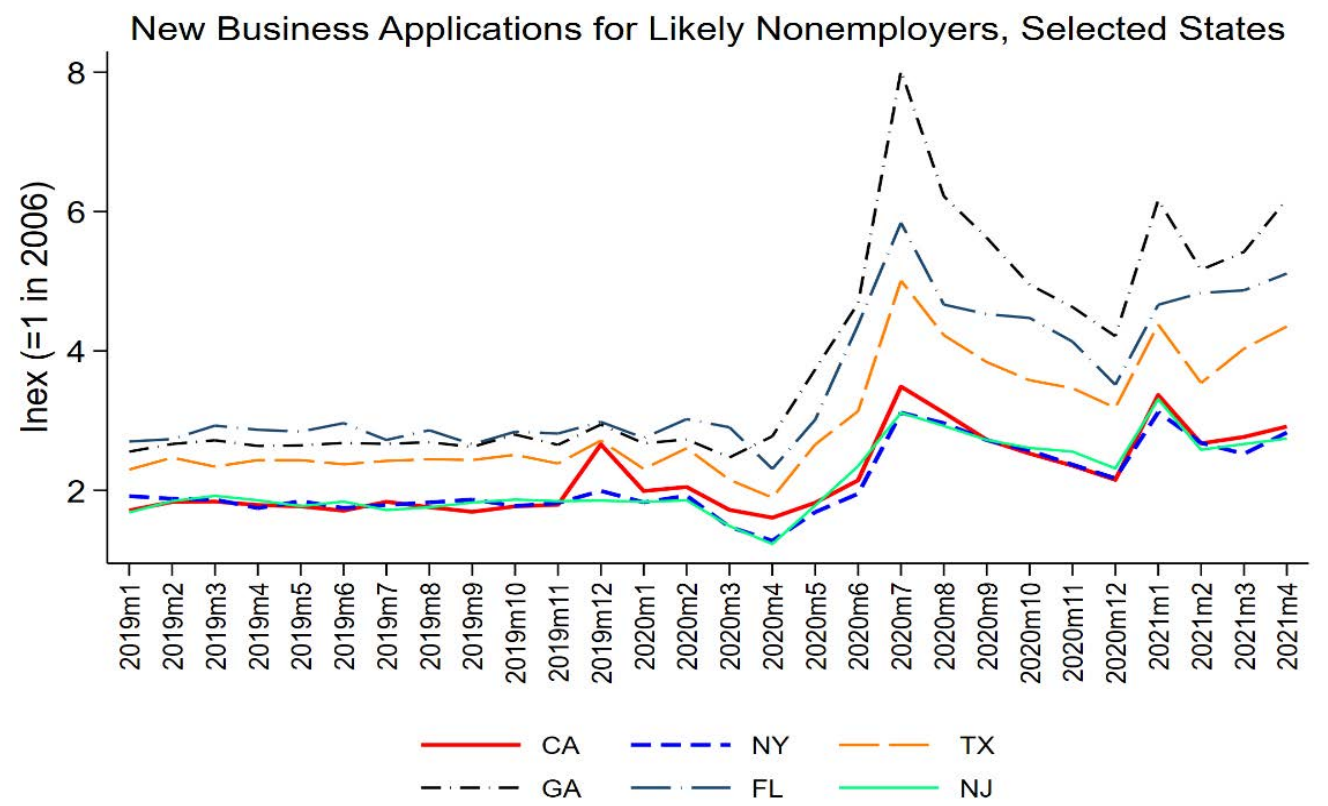

Source: BFS 
Figure 11. Dispersion in Between State Net Growth Rates for Likely Employers (HBA) and Nonemployers (NHBA)

A. 2005:m7-2021:m4

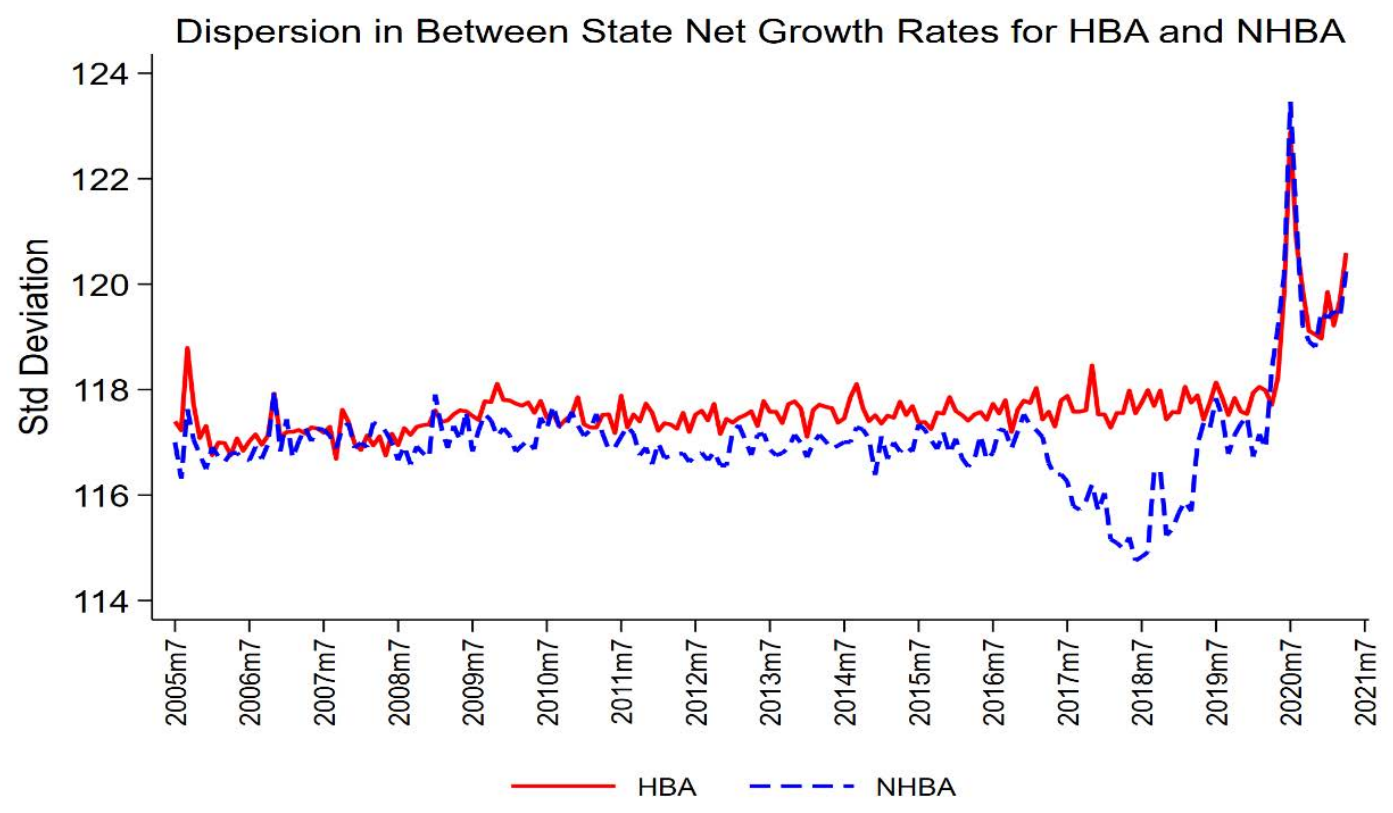

B. 2019:m1-2021:m4

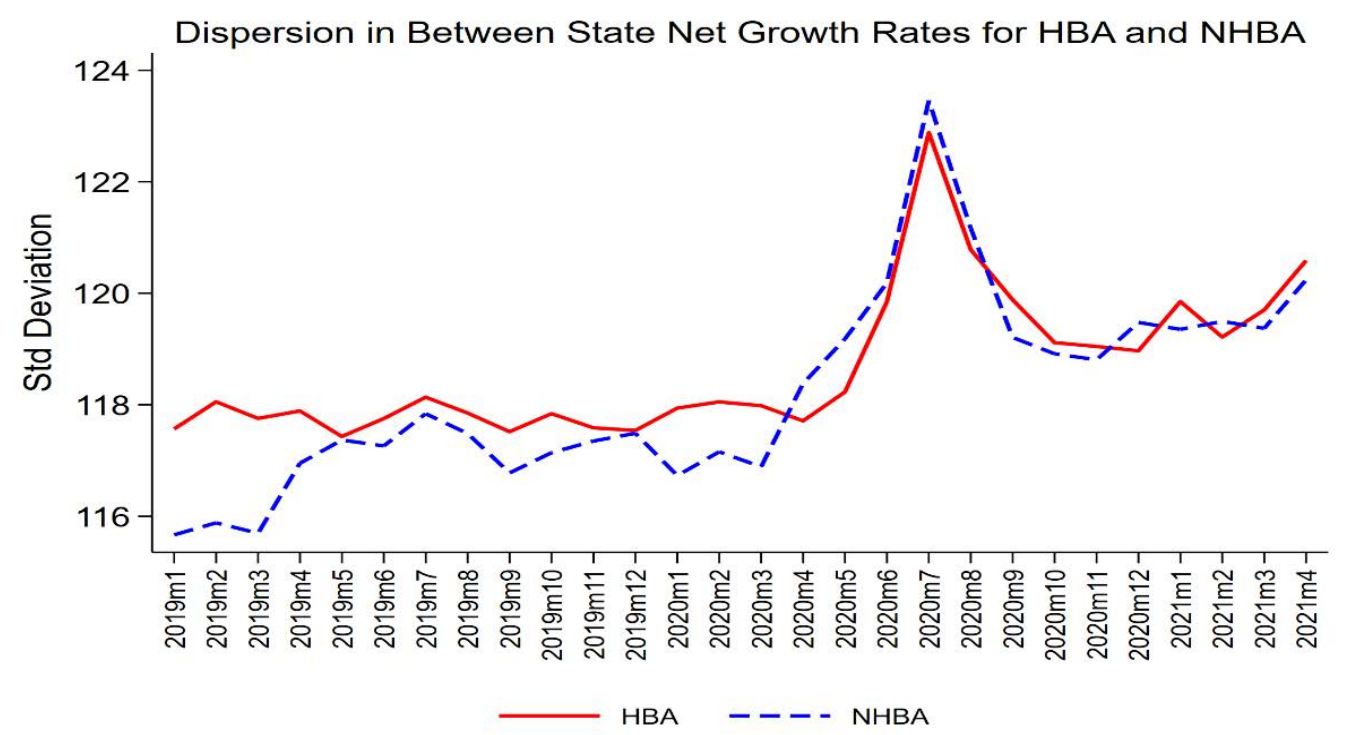

Notes: Source: BFS. Standard deviation of $\mathrm{Y} / \mathrm{Y}$ monthly growth rates across 2-digit NAICS sectors. 
Figure 12. Cumulative Impulse Response of Establishment Birth and Death Rates to HBA Growth Innovation

A. Establishment Birth Rate

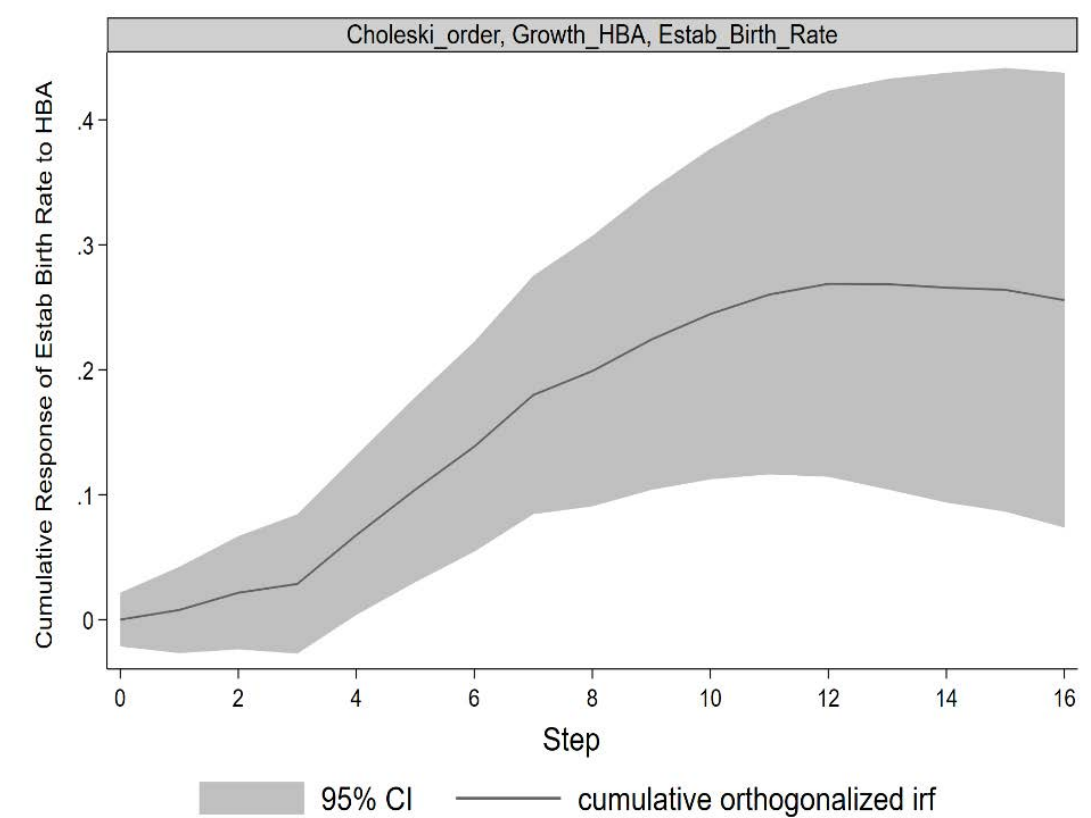

Graphs by irfname, impulse variable, and response variable
B. Establishment Death Rate

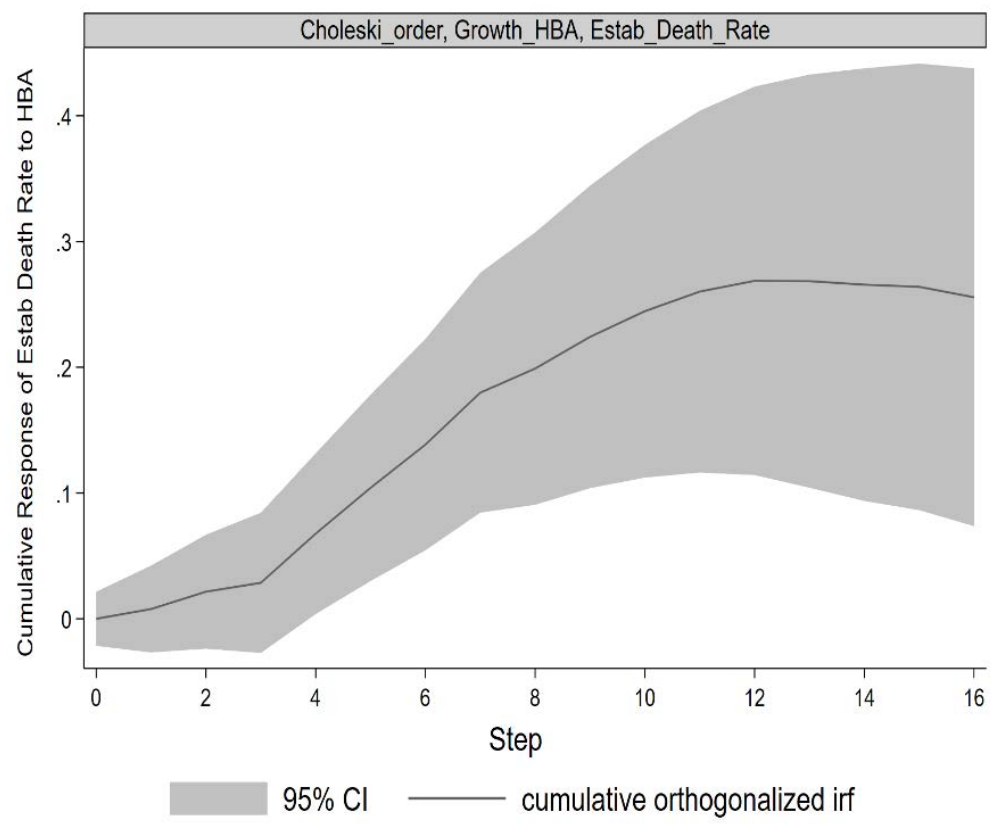

Graphs by irfname, impulse variable, and response variable

Source: BFS (aggregated to quarterly frequency) and BED from 2004:3-2019:4. Bivariate VARS (panel A with Growth in HBA and Establishment Birth Rate and panel B with Growth in HBA and Establishment Death Rate) lags equal to 8. Steps refer to quarters. 
Figure 13. Cumulative Impulse Response of Hires and Separations Rates to HBA Growth Innovation

A. Hires Rate

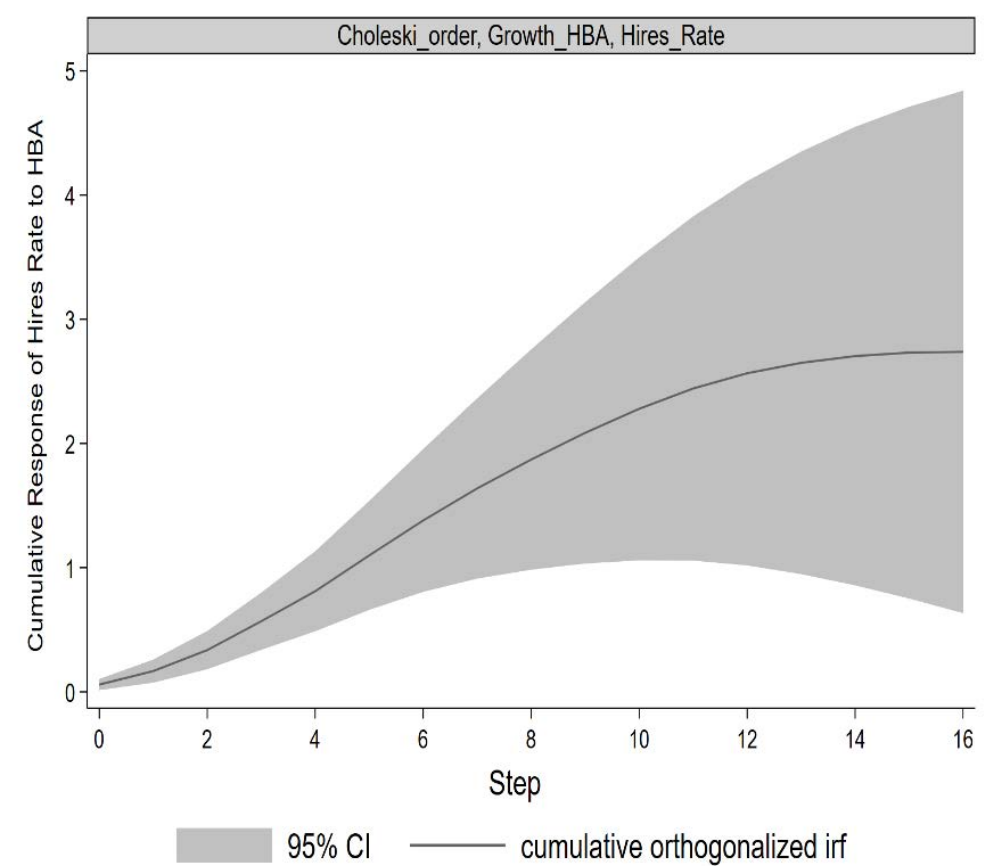

Graphs by iffname, impulse variable, and response variable

\section{B. Separations Rate}

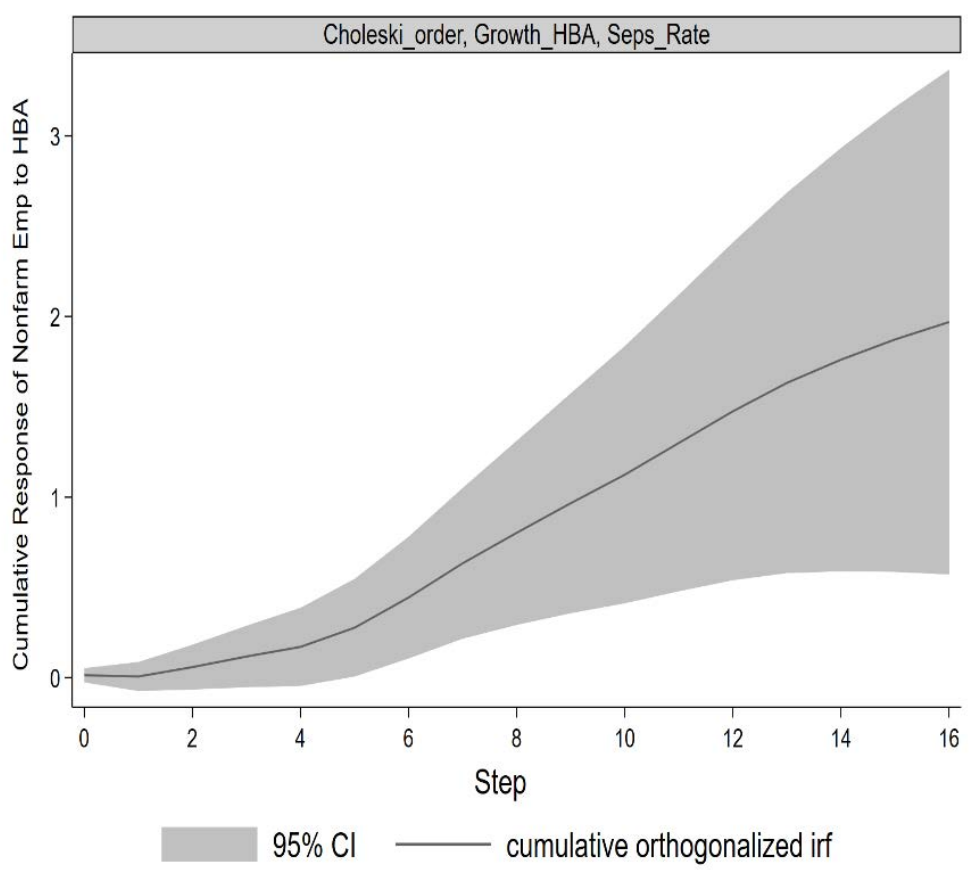

Graphs by iffname, impulse variable, and response variable

Source: BFS and JOLTS aggregated to quarterly frequency from 2004:3-2019:4. Bivariate VARS (panel A with Growth in HBA and Hires Rate and panel B with Growth in HBA and Separation Rate) lags equal to 8. Steps refer to quarters. 
Figure 14. Cumulative Impulse Response of Net Employment Growth and Job Openings Rates to HBA Growth Innovation

A. Net Employment Growth Rate (JOLTS)

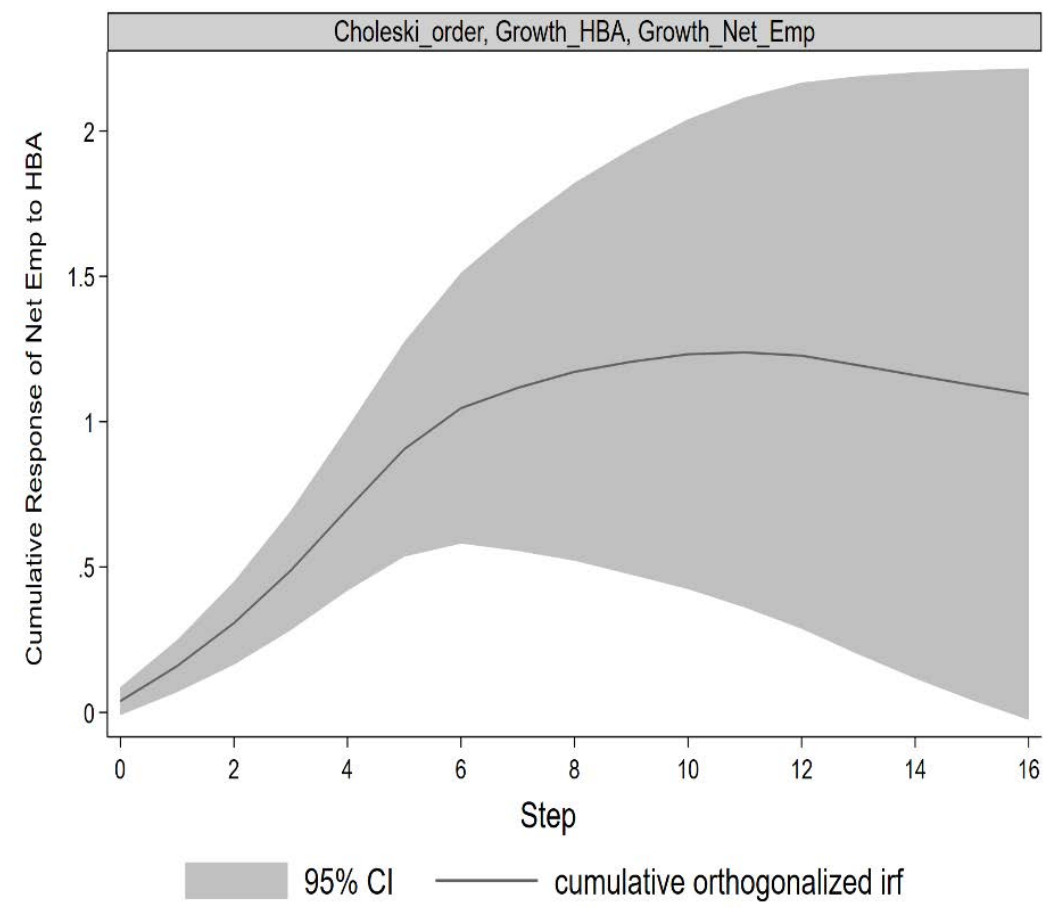

Graphs by irfname, impulse variable, and response variable
B. Job Openings Rate

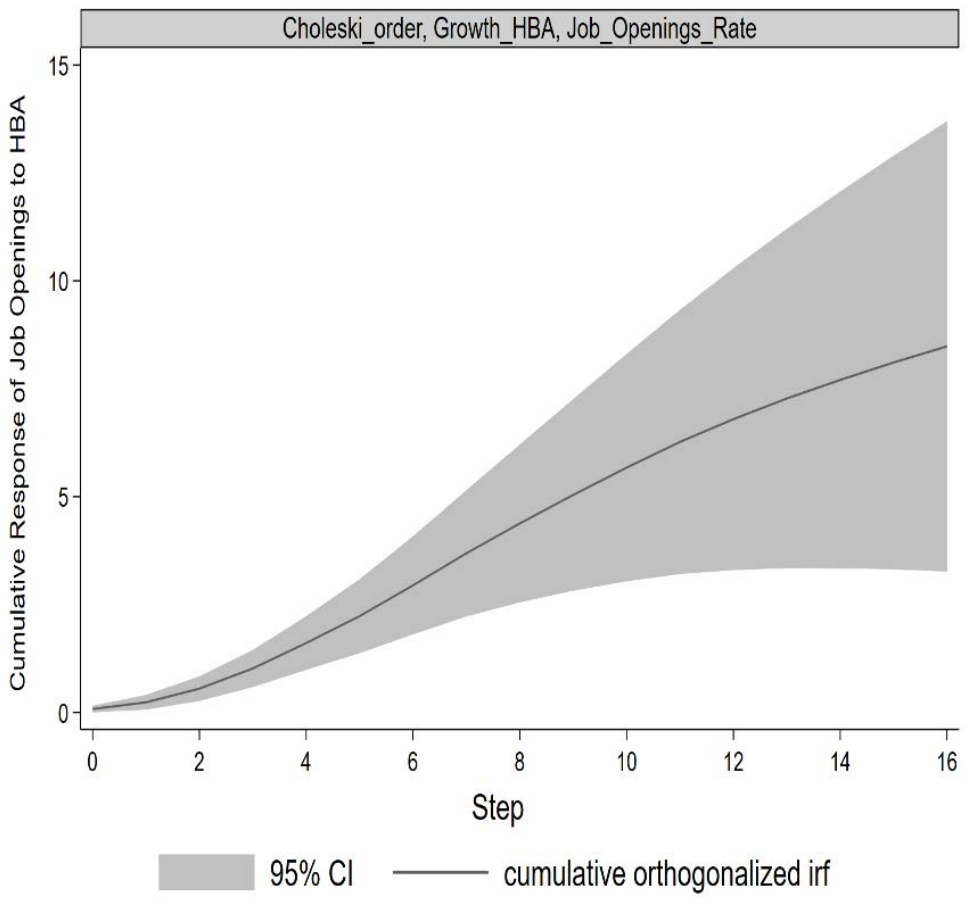

Graphs by iffname, impulse variable, and response variable

Source: BFS and JOLTS aggregated to quarterly frequency from 2004:3-2019:4. Bivariate VARS (panel A with Growth in HBA and Net Employment Growth Rate (Hires Rate-Separations Rate) and panel B with Growth in HBA and Job Openings Rate) lags equal to 8. Steps refer to quarters. 
Appendix

\section{A. Projected Nonemployers}

Figure 3 depicts projected nonemployers from NHBA using the following transition equation:

$$
N E S_{t}=\left(1-\text { ExitRate }_{t}\right) N E S_{t-1}+N H B A_{t}
$$

The exit rate is estimated from Davis et al. (2009). Appropriate caution is needed in using this measurement approach since NES includes sole proprietor, non-employers not captured in NHBA. The index number approach in Figure 3 alleviates implied level differences but the lack of information on entry of sole proprietor, non-employers still suggests caution.

\section{B. VAR specifications}

For section IV, the VAR relationships are specified as follows:

$$
Z_{t}=A(L) Z_{t}+v_{t}
$$

where $\mathrm{Z}_{t}$ is a vector of observable variables, $L$ is the lag operator and $v_{t}$ is a vector of reduced form innovations. The analysis in section IV focuses on simple bivariate VAR specifications with, for example, the growth rate of HBA as one variable and business and worker turnover indicators as the other variable. Insights from the VAR emerge from inverting the AR representation in (1) to the MA representation given by:

$$
Z_{t}=M(L) v_{t}=S(L) \eta_{t}
$$

where $M(L)$ are the MA coefficients from inverting the AR representation and $\eta_{t}$ represents the innovations to each of the orthogonalized "structural" innovations after making some identifying assumptions. ${ }^{25}$ Specifically, a Choleski recursive structure is used for this identification. In the results reported in section IV, HBA is chosen as first in the causal ordering. However, unreported results show the patterns in Figures 12-14 are largely robust to changing the causal ordering. While this might be surprising, it is important to remember that this is imposing restrictions on the covariance structure of the structural innovations relative to the reduced form residuals. The latter reflect the period t residual after controlling for lags of the variables in $\mathrm{Z}_{\mathrm{t}}$.

The business and worker turnover measures used are as follows: establishment birth rate in Figure 12a from the BED, establishment death rate in Figure 12b from the BED, hires rate in

\footnotetext{
${ }^{25}$ By definition, the MA coefficients for the current period 0 in terms of the reduced form residuals is the identity matrix, $\mathrm{M}(0)=I$. Of greater interest is to specify the MA representation in terms of orthogonalized innovations. This requires identifying assumptions. A common set of identifying assumptions is to use the Cholesky decomposition which imposes short run restrictions on the relationship between the contemporaneous reduced form residuals and the orthogonalized innovations. Let $\mathrm{S}(0)=S_{0}$ and let the relationship be $\eta_{t}=S_{0} v_{t}$ and $\mathrm{S}(L)=M(L) S_{0}$. Under Cholesky, $\mathrm{S}_{0}$ is lower triangular so that identification is through assuming a recursive structure. In a two variable VAR under Cholesky, all of the covariance between the reduced form residuals is attributed to the orthogonalized innovation for the variable specified first in the VAR.
} 
Figure 13a from JOLTS, separations rate in Figure 13b from JOLTS, net employment growth rate (hires minus separations rate from JOLTS) in Figure 14a, and job openings rate in Figure 14b from JOLTS. All rates are measured as percent of employment. The HBA growth rate is the quarterly log first difference multiplied by 100 .

For these specifications, the lag length is 8. Unreported results show robustness to alternative lag lengths. While results are robust on several dimensions, appropriate caution is required in interpreting the VAR results since they are simple bivariate specifications. The results provide insights into the dynamic covariance structure between HBA and indicators of business and worker turnover. More research is needed to understand the mechanisms underlying the reported results.

Supporting evidence using closely related VAR analysis is presented in Asturias et al. (2021). The latter investigates the relationship between HBA growth rate innovations and Principle Federal Economic Indicators (PFEIs). Using data at the monthly frequency (since most PFEIs are monthly) and using bivariate VAR specifications, they find that an innovation to HBA growth yields a substantial increase in the growth rate of non-farm payroll employment that peaks at about 12 months but persists for more than 24 months. Putting the pieces together, the findings in the current paper highlight that an innovation in HBA growth yields substantial persistent increases in business and worker turnover. The Asturias et al. (2021) results show there is also a substantial persistent increase in net employment growth. Thus, a surge in HBA is associated by an increase in both net and gross flows.

\section{PPP and New Business Applications: Further Discussion}

The primary group of PPP recipients that may have been induced to apply for an EIN by the program directly are sole proprietor, nonemployers that did not have an EIN prior to applying for a PPP loan. Using SBA data on all loans, about $600 \mathrm{~K}$ of the 5.2 million PPP loans by August 2020 went to sole proprietor, nonemployers. This is an upper bound on the number of PPP loan recipients that also applied for a new EIN after February 2020. ${ }^{26}$ This upper bound is relatively small compared to almost 4 million new business applications from May 2020 to January 2021

An EIN was not required for the PPP application, but it is possible that some of this group may have applied for an EIN as part of this process. This may have occurred before or after receiving a first-round loan. For example, sole proprietor, nonemployers using an SSS as the Taxpayer Identification Number (TIN) for their loan application may have applied for an EIN after receiving a loan as having a business checking account facilitates managing the PPP financial reporting. Relatedly, it has been reported that some draw 2 PPP loan applications have experienced delays in processing for those applications with a TIN mismatch between round 1 draw 1 loan and round 2 draw 2 application. This mismatch could occur for those sole proprietors, nonemployers that used their SSN in round 1 and an EIN in round 2. The upper bound on such mismatches is low relative to the total number of EIN applications from May 2020 to January 2021

\footnotetext{
${ }^{26}$ For SBA data on all loans see https://www.sba.gov/funding-programs/loans/coronavirus-relief-options/paycheck-
} protection-program/ppp-data\#section-header-2. 
It is also worth emphasizing that the surge in new business applications is not just in overall applications but also in applications for likely new employers (HBA and WBA). For employer businesses getting PPP loans, they must have had an EIN pre-pandemic so this pandemic surge in HBA and WBA cannot be accounted for by the PPP program. The surge in HBA and WBA applications (see Figure 1 and Figure B.1) is roughly proportional to the surge in overall applications. If the PPP program had a large impact on EIN applications by existing nonemployers without an EIN, one would expect that BA would have risen much more sharply than HBA or WBA. This approximate proportionality holds in the recent second surge in January 2021 implying that the second round of PPP is not the primary driving factor for this second surge.

Figures 1 and B.1 do show that BA rose more rapidly than HBA and WBA in the July 2020 and January 2021 surges. However, these surges are primarily accounted for new applications in NAICS 454 (Nonstore Retail) as seen in Figure 7. Nonstore Retailers has traditionally been a nonemployer intensive industry. In 2018, 92\% of Nonstore Retail businesses were nonemployers. It is not obvious why PPP should have generated a surge in nonemployer applications Nonstore Retail. 
Figure B.1. Indices of Business Applications (BA) and Those with Planned Wages (WBA), 2019:m12021:m4

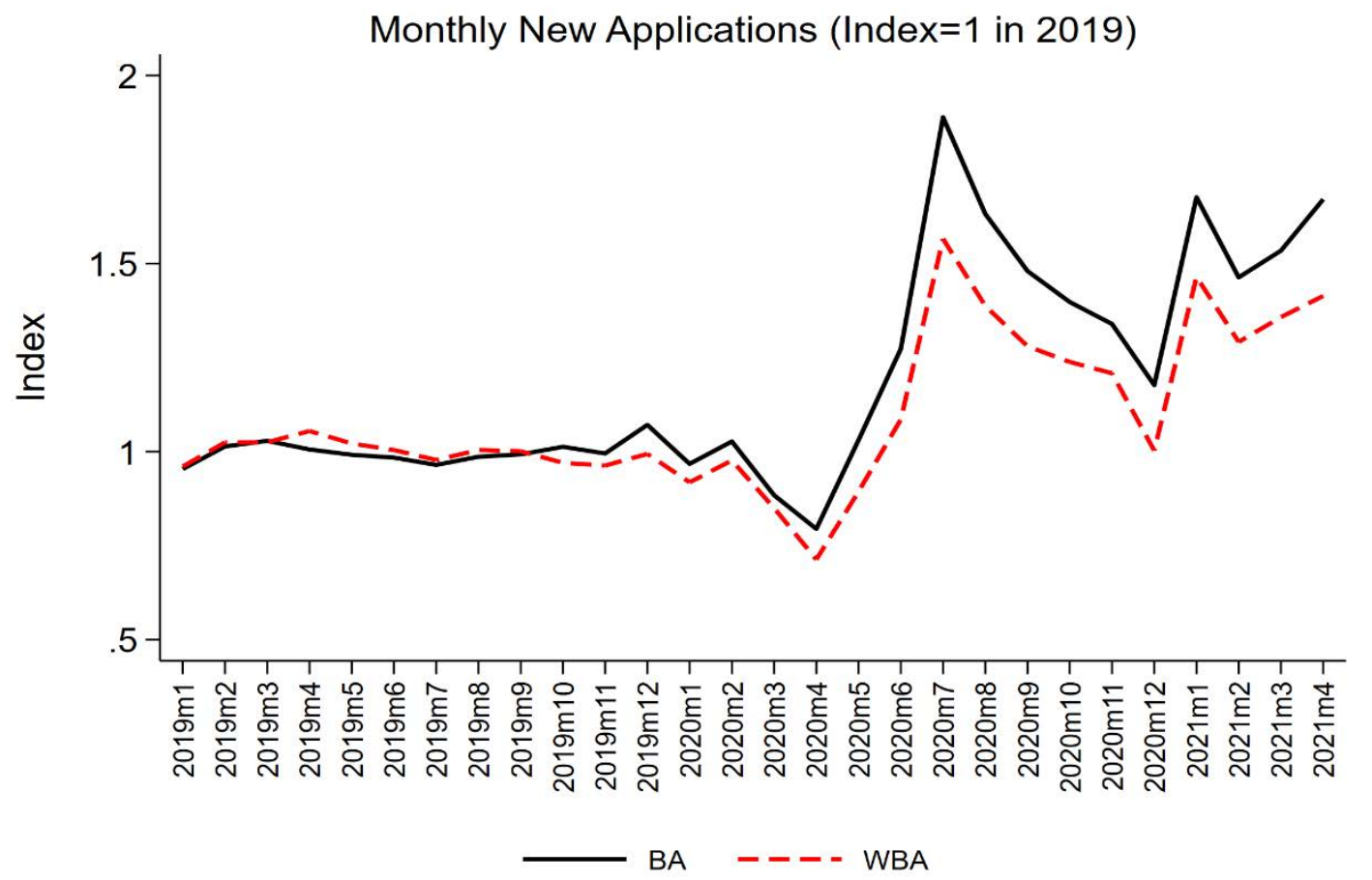

Source: BFS 